\title{
Article \\ Optimal Design and Dynamic Analysis of Hydrofoil Mechanism of Wave Glider
}

\author{
Hongqiang Sang ${ }^{1}$, Jin Zhang ${ }^{1}$, Xiujun Sun ${ }^{2, *}$, Can $\mathrm{Li}^{3}$, Lei Wang ${ }^{4}$ and Liwei Wang ${ }^{4}$ \\ 1 School of Mechanical Engineering and Tianjin Key Laboratory of Advanced Mechatronic Equipment \\ Technology, Tiangong University, Tianjin 300387, China; sanghongqiang@tiangong.edu.cn (H.S.); \\ 1931055343@tiangong.edu.cn (J.Z.) \\ 2 Physical Oceanography Laboratory, Ocean University of China, Qingdao 266100, China \\ 3 Institute for Advanced Ocean Study, Ocean University of China, Qingdao 266100, China; lican@ouc.edu.cn \\ 4 Research and Development Department of Wave Glider Tsingtao Hydro Technology Co., Ltd., \\ Qingdao 266100, China; wanglei92000553@hotmail.com (L.W.); wangliwei18253205703@hotmail.com (L.W.) \\ * Correspondence: sxj@ouc.edu.cn
}

check for updates

Citation: Sang, H.; Zhang, J.; Sun, X.; Li, C.; Wang, L.; Wang, L. Optimal Design and Dynamic Analysis of Hydrofoil Mechanism of Wave Glider. J. Mar. Sci. Eng. 2022, 10, 367 https://doi.org/10.3390/ jmse10030367

Academic Editor: Md Jahir Rizvi

Received: 19 January 2022

Accepted: 25 February 2022

Published: 4 March 2022

Publisher's Note: MDPI stays neutral with regard to jurisdictional claims in published maps and institutional affiliations.

Copyright: (C) 2022 by the authors. Licensee MDPI, Basel, Switzerland. This article is an open access article distributed under the terms and conditions of the Creative Commons Attribution (CC BY) license (https:// creativecommons.org/licenses/by/ $4.0 /)$.

\begin{abstract}
A wave glider can convert vertical wave motion into its forward propulsion. There are many factors affecting the propulsion performance of a wave glider. The swing amplitude of hydrofoil can affect the efficiency of hydrofoil to capture wave energy, and the pull direction of an umbilical cable can affect the transmission efficiency of wave energy. In this paper, an optimized hydrofoil mechanism with a self-adjusting lower limit (SALL) was proposed by analyzing the un- synchronized movement between the submerged glider and the surface float. This mechanism was able to transfer the movement of umbilical cable to the hydrofoil swing mechanism through the linkage to control the lower limit of hydrofoil swing (maximum swing angle of hydrofoil in a counterclockwise direction). Firstly, the user-defined function (UDF) was written to control the motion of hydrofoil in the fluid domain. The lower limit swing angle and the heave direction of the hydrofoil were both set in the UDF, and the forward thrust generated by the passive swing of the hydrofoil in the fluid domain was able to be obtained by the simulation. Secondly, the prototype was designed by introducing a parallelogram mechanism on a conventional submerged glider, and a wave simulation test platform was built to verify the propulsive performance of the prototype. The results showed that, in comparison with the conventional submerged glider, the forward thrust of the SALL submerged glider was able to be improved by $1.50 \%, 17.78 \%, 7.42 \%$, and $20.70 \%$ under the stiffness coefficients of torsion spring set to $K=2, K=4, K=6$, and $K=8$ in the simulation experiment, respectively. The forward thrust of the SALL submerged glider was able to be elevated by $9.99 \%$ with torsion spring $\mathrm{K}=8$ in the tank experiment. The advantage of the SALL mechanism was verified by comparing the results of the simulation and the tank experiment. Finally, the feasibility of the SALL submerged glider was verified in actual sea conditions by a sea trial.
\end{abstract}

Keywords: wave glider; submerged glider; self-adjusting lower-limit (SALL) mechanism; umbilical cable inclination angle; propulsive performance

\section{Introduction}

The wave glider is a new type of unmanned mobile observation platform, consisting of a surface float, a submerged glider, and an umbilical cable, the latter of which is used to connect the surface float and the submerged glider [1]. Wave gliders rely on wave energy to obtain a continuous forward thrust, and electric energy is generated by solar panels on the surface float [2], which can realize large-scale and long-time marine environmental monitoring. The speed of the wave glider is an important index to evaluate its performance. The higher the speed, the stronger the ability of the resistance ocean current, and the higher the control precision. Therefore, the way in which to increase the speed of the wave glider has become a research hotspot. The wave power conversion efficiency of the submerged 
glider plays a decisive role in affecting the speed of the wave glider. Thus, it is very important to develop an efficient submerged glider with a special hydrofoil mechanism.

A computational fluid dynamics (CFD) method was used to simulate and analyze the propulsive performance of longitudinal hydrofoil of the wave glider [3]. The single 2D hydrofoil was systematically studied, and the best propulsive performance within a range of velocities was found by studying the influences of changing the axis position and torsional elastic stiffness. The propulsive performance of six pairs of tandem hydrofoils was analyzed by changing the amplitude and torsional stiffness. The results showed that compared with the pivot position, the torsion spring played a key role in the propulsive performance. The passive pitching angle of the hydrofoil arranged in the middle of tandem hydrofoils was greater than that of the stem and stern hydrofoil and showed more stable sinusoidal movement, and the forward thrust of the middle hydrofoil was greater than that of the other hydrofoils in the fore-and-aft direction. The effects of pitching frequency, spring stiffness, and pitching amplitude were studied on the hydrodynamic characteristics of a semi-active flapping wing [4]. For the sinusoidal pitching, the effects of the pitching amplitude and the reduced frequency were investigated. The non-sinusoidal pitching and the influence of pitch angle from sinusoidal to square wave on propulsion efficiency were studied. It was found that the critical pitch amplitude could improve the average output power coefficient and the propulsive efficiency of the semi-active flapping wing. A two-dimensional numerical simulation method was used to study the performance of the semi passive flapping wing energy harvester with Reynolds number of 5000-50,000. The energy harvester consisted of NACA0015 airfoil, which was supported by a translational spring and a damper. After the sinusoidal pitching motion was input to the hydrofoil, energy was extracted from the flow-induced vibration of the hydrofoil in the translational mode, and the motion of the hydrofoil could be adjusted in the fluid domain by using a mixed Cartesian fluid grid. It was found that the energy capture efficiency of the hydrofoil could be improved with a high Reynolds number; when the pitch amplitude $\theta_{0}=30^{\circ}$ and $\operatorname{Re}$ (Reynolds numbers) $=20,000$, the power extraction efficiency reached as high as $16 \%$. In addition, the reattachment of the leading-edge separation vortex played an important role in the propulsive performance of the whole hydrofoil system [5]. The structure of a kind of square wing plate with a bad hydrodynamic performance was optimized [6]; by calculating the best sweep angle and leading-edge radius of the rectangular hydrofoil, the structural dynamic sensitivity analysis and matrix perturbation theory were combined, and a proper guidance of structural modification was established. The finite element analysis and experimental modal test were used to study the dynamic characteristics of the optimized hydrofoil. The results showed that the proposed optimization method could improve the hydrodynamic performance of the hydrofoil.

The effects of the difference connection structures between the surface float and the submerged glider on the propulsive performance of the wave glider were studied [7]. Various connection types such as rigid rod cable, multi-link chain, and elastic rod were used to connect the surface float and the submerged glider. The propulsive performance of the wave glider was analyzed by using the numerical method under the difference connection structure types. The simulation results showed that there were little differences in the propulsive performance of wave gliders with different connection types. However, serious impacts could occur on the connections of rigid rod and multi-link chain, which would make extra load act on the structure of the wave glider. The dynamic model of the wave glider considering the influences of the flexibility of the umbilical was proposed, and the numerical simulations of longitudinal and rotary motions of the wave glider were performed. The results showed that the umbilical was not always under tension. When the wave surface fell rapidly under high wave conditions, the umbilical easily became slack. The $X-Z$ view of the wave glider showed that the surface float ran ahead of the submerged glider [8].

In the above studies, the effects of the umbilical cable, the structure, and the swing mode of the hydrofoil on the propulsive performance of the wave glider were analyzed. 
However, the influence of an umbilical cable inclination angle on the propulsive performance was ignored in the actual conditions, and there was no research about the influence of umbilical cable inclination angle on propulsive performance.

The pulling force of the umbilical cable acts vertically on the frame of the submerged glide in above studies, which is not in line with the actual situation. The frame of the submerged glider is kept horizontal and is always moved in front of the surface float; therefore, there is always a dynamic umbilical cable inclination angle $\gamma$ between the umbilical cable and the vertical direction, which is shown in Figure 1. When the umbilical cable pulls the submerged glider backward and upward, the hydrofoil with a relatively fixed lower limit swing angle cannot efficiently realize wave power conversion. Therefore, the submerged glider with a lower limit of the hydrofoil that varies with the umbilical cable inclination angle is more suitable for the actual working condition of the wave glider. The main contributions of this paper can be summarized as follows:

(1) A submerged glider with the self-adjusting lower-limit (SALL) is proposed. The effect of the umbilical cable inclination angle on the hydrofoil is considered, and the lower limit of the hydrofoil can be regulated according to the umbilical cable inclination angle. Thus, the submerged glider can make full use of the vertical pulling force transmitted from the surface float through the umbilical cable.

(2) A method of buffering and energy storage by adding torsion spring after the hydrofoil swings at a fixed angle is proposed, and the damping moment of initial swing of the hydrofoil is reduced, potentially improving the propulsive applicability of the wave glider under different sea conditions.

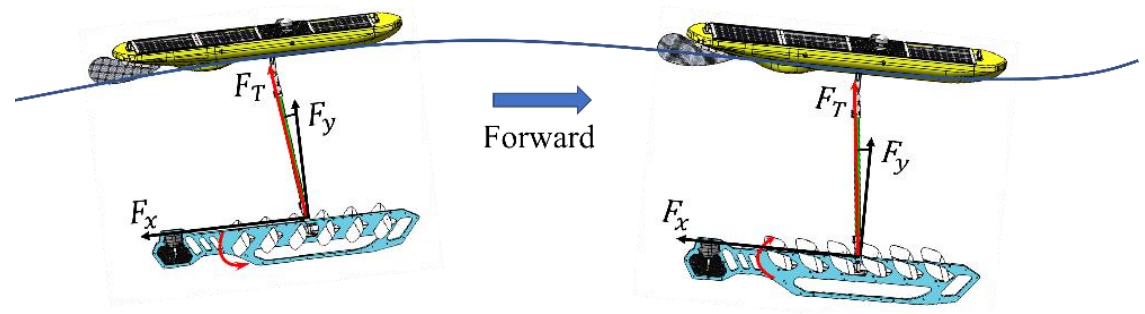

Figure 1. Umbilical cable inclination angle of the wave glider.

The rest of this paper is organized as follows. In Section 2, the dynamic model of the "Black Pearl" wave glider and the design of the SALL mechanism are briefly introduced. In Section 3, the forward thrust simulation results of a pair of hydrofoils under the conventional submerged glider and the SALL submerged glider are elucidated in detail. As outlined in Section 4, considerable tank experiments were performed to evaluate the performance of the SALL submerged glider, and a sea trial was performed under real sea conditions. In Section 5, the main conclusions are drawn.

\section{Structural Optimization and Dynamic Modeling of the "Black Pearl" Wave Glider}

The "Black Pearl" wave glider was developed by the Ocean University of China, Tiangong University, and Tsingtao Hydro Technology Co., Ltd. The movement principle of the wave glider is shown in Figure 1. Under the effect of wave action and its own gravity, the surface float will rise or fall on the sea surface. When the surface float rises, the submerged glider will move up under the pulling force of the surface float through an umbilical cable, and the hydrofoils will rotate downward under the hydraulic resistance on their upper surfaces. When the surface float falls, the submerged glider will sink because of its own gravity, and the hydrofoils rotate upward under the hydraulic resistance on their lower surfaces [9].

\subsection{Limitations of the Conventional Submerged Glider}

The surface float can rise rapidly by positive buoyancy from trough to crest. The umbilical cable inclination angle can change the pulling direction of the umbilical cable 
and make the umbilical cable pull the submerged glider backward and upward. However, the effective force caused by wave energy is still transmitted along the vertical direction. The umbilical cable inclination angle will cause the loss of wave energy and reduce the conversion efficiency of wave energy. Although high-level sea states can significantly increase the forward velocity of the wave glider, a larger umbilical cable inclination angle will be generated. Therefore, the energy loss will be more obvious.

To study the wave propulsion mechanism of the wave glider, we decomposed the coupled motion of the hydrofoil into the heaving motion and pitching motion, as shown in Figure 2, where $c$ is the chord length of the foil, $\theta$ is the pitch angle, and the pivot point is located at $c / 3$ of the chord.

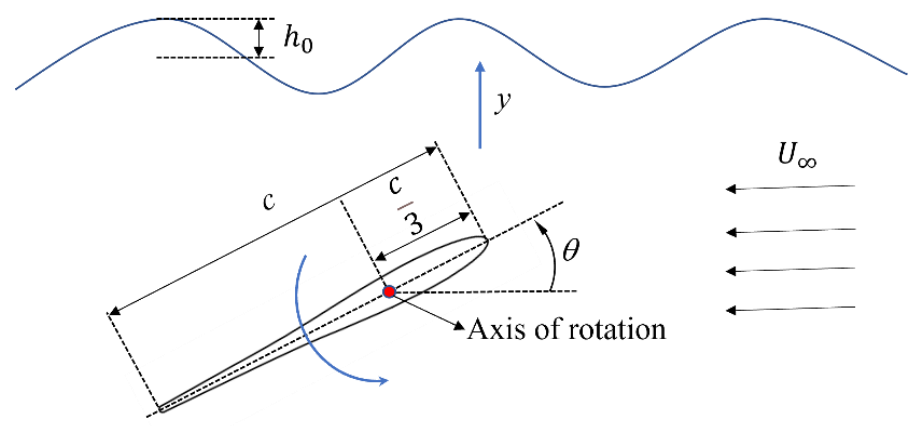

Figure 2. Schematic illustration of the coupled motion of the hydrofoil.

In accordance with [10], the gravity and buoyancy of the hydrofoil was ignored, and the pitching motion was completely determined by the hydrodynamic force and torsion spring. The passive swing motion of the hydrofoil can be defined as

$$
\left\{\begin{array}{l}
y(t)=h_{0} \sin (2 \pi f t) \\
\ddot{\theta}=M(t)+M_{G}+K \theta(t)
\end{array}\right.
$$

where $t$ is the motion time, $f$ is the motion frequency, $h_{0}$ is the amplitude of the vertical motion, $J$ is the moment of inertia of the hydrofoil around the center of mass, $\ddot{\theta}$ is the angular acceleration of the hydrofoil, $M(t)$ is the leading-edge hydrodynamic moment of the hydrofoil, $M_{G}$ is the gravitational moment of the hydrofoil, and $K$ is the stiffness coefficient of the spring.

\subsection{Improvement and Description of the SALL Mechanism}

In the moving process of the wave glider from peak to trough, the umbilical cable is in a relaxed state. The submerged glider will move down due to its own gravity and is not affected by the waves. According to engineering experience and related reference [11], the hydrofoil is limited to a fixed gliding angle of $20^{\circ}$. Thus, the upper limit swing angle of the hydrofoil of the "Black Pearl" wave glider will remain unchanged, and only the lower limit is improved in this paper.

The umbilical cable inclination angle of the wave glider always exists in the actual conditions. Therefore, a new hydrofoil with a parallelogram mechanism was designed to make the lower limit of the hydrofoil be dynamically self-adjusted according to the umbilical cable inclination angle, which can reduce the loss of wave energy.

For the submerged glider, the swing angle of the hydrofoil being too large or too small will affect the efficiency of capturing wave energy. The SALL submerged glider can maintain a fixed gliding angle $\varphi$ between the initial swing angle of the hydrofoil and the umbilical cable, and the comparisons of the hydrofoil and the structure are shown in Figures 3 and 4 . It can be seen that the hydrofoil will swing at a fixed angle and can be buffered and limited by using a torsion spring. 


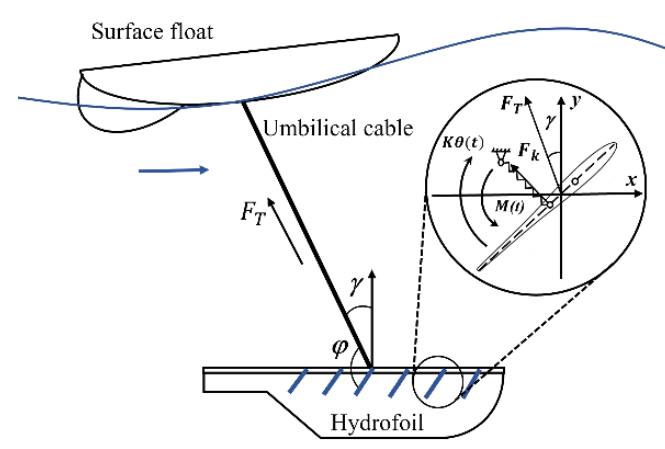

(a)

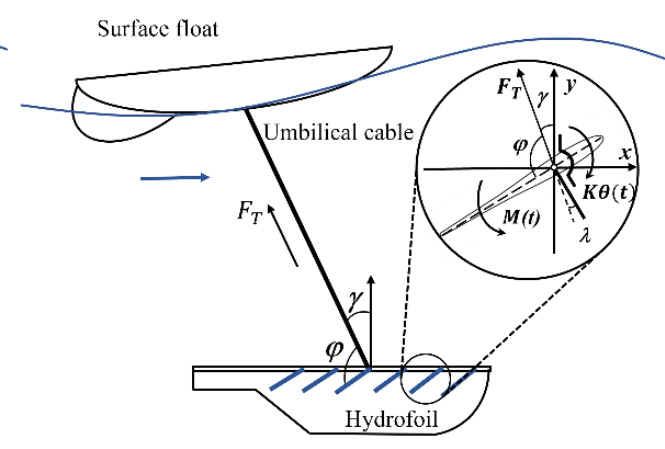

(b)

Figure 3. The hydrofoil comparison of the SALL submerged glider and the conventional submerged glider during ascent phase. (a) Conventional submerged glider; and (b) self-adjusting lower-limit submerged glider.

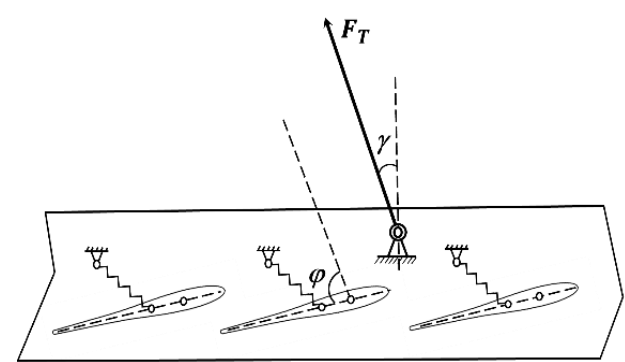

(a)

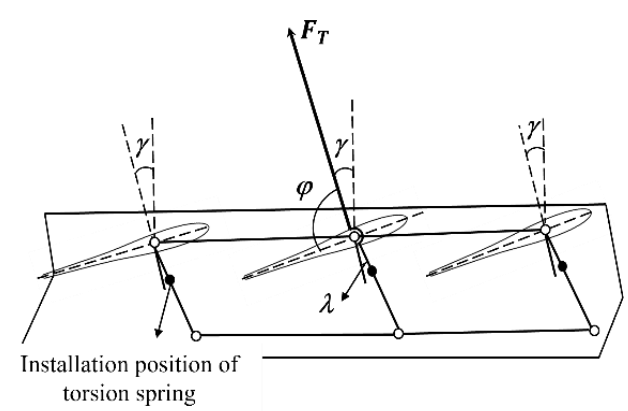

(b)

Figure 4. The structure comparison of the SALL submerged glider and the conventional submerged glider. (a) Conventional submerged glider; and (b) self-adjusting lower-limit submerged glider.

According to [12], the passive swing of the hydrofoil can be defined as

$$
\left\{\begin{array}{c}
y(t)=h_{0} \sin (2 \pi f t) \\
J \ddot{\theta}=M(t)+M_{G} 0 \leq \theta \leq(\gamma+\lambda) \\
J \ddot{\theta}=M(t)+M_{G}+K \theta(t) \theta \geq(\gamma+\lambda)
\end{array}\right.
$$

where $\lambda$ is defined as a follow-up angle, an adjustable parameter that can be adjusted by changing the installation position of the torsion spring, and the angle of $\varphi$ can be changed by adjusting $\lambda$; the relationship between $\lambda$ and $\varphi$ can be expressed as

$$
\varphi=\lambda+90
$$

The principle of the SALL submerged glider can be described as follows: the waves have great randomness; when the wave glider moves from trough to crest, there will be two cases. When the wave height is small, the hydrodynamic moment of the hydrofoil is small; it can be seen from Equation (1) that the hydrofoil of the conventional submerged glider always bears the torsion spring torque during the whole swing process. The existence of torque will prevent the swing of the hydrofoil, and it is difficult for the hydrofoil to swing an appropriate angle to capture wave energy. It can be seen from Equation (2) that the SALL submerged glider does not bear the resistance of the torsion spring before the hydrofoil swings $\gamma+\lambda$. Even though the wave height is small at this time, the hydrofoil can also swing at a certain angle to capture wave energy, as shown in Figure 5. 


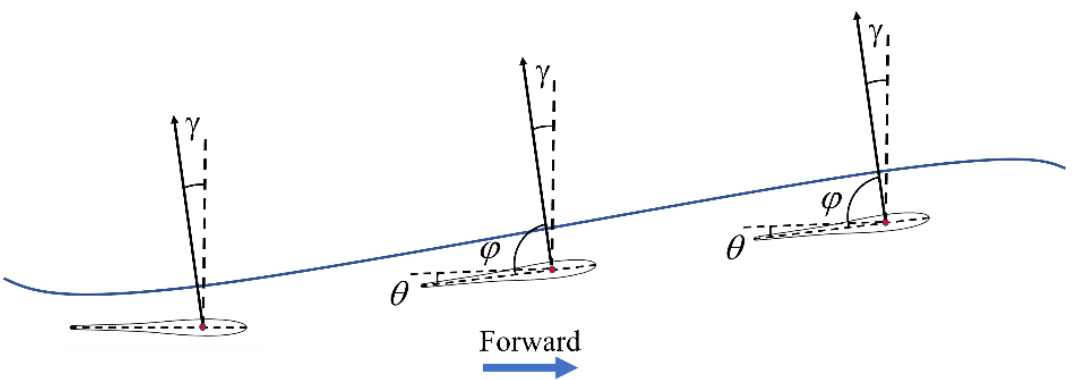

(a)

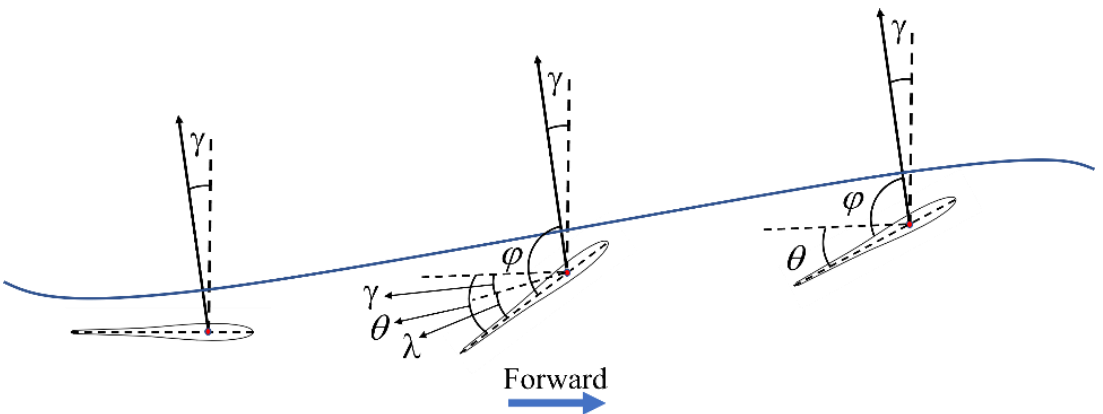

(b)

Figure 5. The wave glider moves from trough to crest with the small wave height. (a) Conventional submerged glider; and (b) self-adjusting lower-limit submerged glider.

When the wave height is high, the hydrodynamic moment of the hydrofoil is large, and the hydrofoil of the conventional submerged glider will swing at a large angle. In this process, the hydrofoil can efficiently capture wave energy only in some angle ranges. For the SALL submerged glider, the torsion spring and the umbilical cable connector are fixed on the two opposite sides of the parallelogram. When the swing angle of the hydrofoil exceeds $\gamma+\lambda$ and the torsion spring is touched, the torsion spring will transmit the torque to the umbilical cable connector through the parallelogram mechanism. Meanwhile, the swing of the umbilical cable connector is also transmitted to the torsion spring through the parallelogram mechanism, which will make the movement of the torsion spring follow up with the umbilical cable and can keep a relatively fixed angle $\varphi$ between the pull direction of the umbilical cable and hydrofoils. The angle $\varphi$ can be adjusted by changing the follow-up angle $\lambda$. The parallelogram mechanism controls the lower swing limit of the hydrofoil by transmitting torque so that the hydrofoil can capture wave energy at a relatively fixed and appropriate swing angle. The specific realization method of the parallelogram mechanism is described in the Section 4.1.

The SALL submerged glider can increase the effective time for the hydrofoil to capture wave energy in a single swing cycle.

The advantages of the SALL mechanism can be summarized as

(1) The damping moment of the hydrofoil during the initial swing is reduced, the hydrodynamic torque makes the hydrofoil quickly swing to a predetermined angle, and the response speed of the hydrofoil can be improved.

(2) The lower limit of the swing angle of the hydrofoil can adapt to the change of the umbilical cable inclination angle, and the lower limit of the hydrofoil and the pulling direction of the umbilical cable can keep a relatively fixed gliding angle at all times, which can reduce the loss of wave energy caused by umbilical cable inclination angle and improve the wave energy capturing ability of the hydrofoil.

\subsection{The Dynamic Model of the Wave Glider}

To provide theoretical guidance for fluid simulation and better evaluate the propulsive performance of the SALL submerged glider, we analyzed the forces acting on the hydrofoils 
during the ascending and descending stages of the wave glider and established the three degrees of freedom dynamic model of the "Black Pearl" wave glider in the longitudinal vertical plane. Four coordinate systems were developed to establish the dynamic model of the wave glider [11,13], which can be expressed as

(1) The geodetic coordinate system: The geodetic coordinate system is also called the inertial coordinate system. Point $E$ is the origin of the coordinate, which is the deployment point of the wave glider. The $X_{e}$ axis points to true North, and the $Z_{e}$ axis points to the center of the earth.

(2) The overall coordinate system of the wave glider: The origin of its coordinates is the center of mass $O$ of the wave glider. The $X_{o}$ axis points to the forward direction of the wave glider, and the $Z_{o}$ axis is vertically downward.

(3) The coordinate system of the surface float: The origin of its coordinates is the buoyancy center $F$ of the surface float. The $X_{f}$ axis points to the forward direction of the surface float, and the $Z_{f}$ axis abides by the right-hand rule to be vertically downward.

(4) The submerged glider coordinate system: The origin of its coordinates is the buoyancy center $G$ of the submerged glider. The $X_{g}$ axis points to the forward direction of the submerged glider, and the $Z_{g}$ axis is also vertically downward. Figure 6 provides the coordinate system definition and overall force analysis of the wave glider.

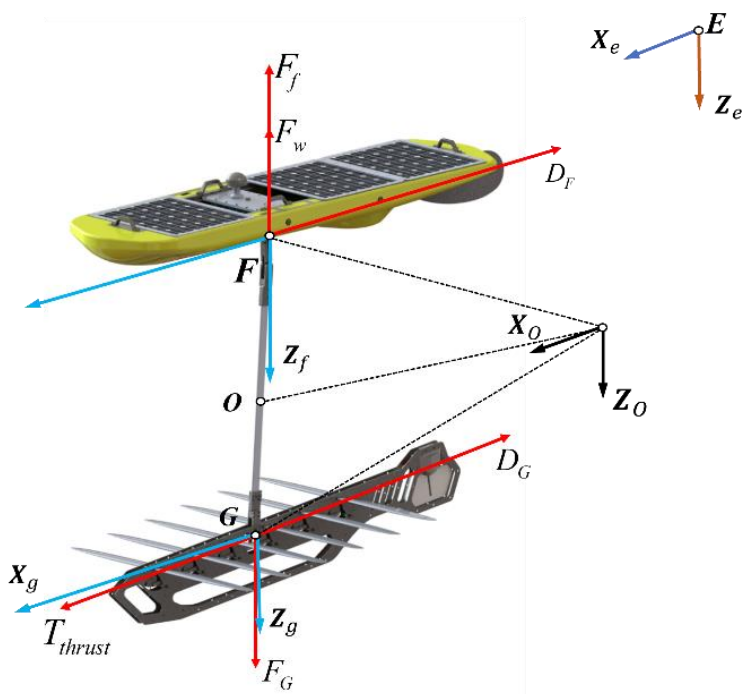

Figure 6. The coordinate system definition and overall force analysis of the wave glider.

The origin of the overall coordinate system of the wave glider was constructed on overall center of mass $O$, the forward direction of the float was defined as the positive direction of $X_{0}$, and the direction perpendicular to the plane of the float was the positive direction of $Z_{o} . F_{f}$ is the buoyancy of the surface float in the vertical direction; $F_{w}$ is the wave force and $D_{F}$ is the reverse resistance of the surface float; $T_{\text {thrust }}$ is the forward thrust of the submerged glider; $F_{G}$ and $D_{G}$ are the gravity and resistance of the submerged glider in the opposite direction, respectively.

As shown in Figure 7, when the wave glider moves from crest to trough, the wave glider is in a steady-state gliding stage, and the wave glider slides down due to the gravity of the submerged glide; $\alpha$ is angle of attack of the hydrofoil, $\beta$ is the angle between the hydrofoil chord and the horizontal plane, and $F_{k}$ is the tension of the spring.

Lift force $F_{L}$ and drag force $F_{D}$ of the hydrofoil can be expressed as

$$
\begin{aligned}
& F_{L}=\frac{1}{2} \rho C_{L} A V^{2} \\
& F_{D}=\frac{1}{2} \rho C_{D} A V^{2}
\end{aligned}
$$


where $\rho$ denotes the seawater density, $V$ represents the relative velocity, $C_{L}$ is the lift force coefficient, $C_{D}$ is the drag force coefficient, and $A$ represents the projected area of the hydrofoil in the direction of lift and drag.

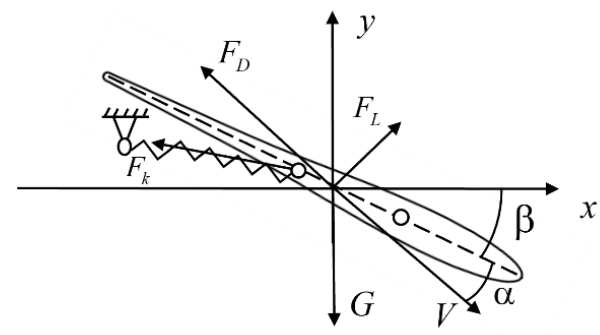

Figure 7. The force analysis of the hydrofoil during the gliding phase.

In this case, the dynamic equation of the wave glider can be described as [14]

$$
\left\{\begin{aligned}
x(k+1) & =x(k)+u(k) d t \\
u(k+1) & =u(k)+\frac{1}{M+\lambda_{11 f}+\lambda_{11 g}}\left(T_{\text {thurst }}+X_{\text {Fuu }} u_{F}\left|u_{F}\right|+X_{G u u} u_{G}\left|u_{G}\right|\right) d t \\
z(k+1) & =z(k)+w(k) d t \\
w(k+1) & =w(k)+\frac{F_{G}}{M+\lambda_{33 f}+\lambda_{33 g}} d t
\end{aligned}\right.
$$

When the wave glider moves from trough to crest, the submerged glider rises rapidly under the pulling force of the positive buoyancy of the surface float. Accordingly, the dynamic equation of the wave glider can be written as

$$
\left\{\begin{array}{l}
x(k+1)=x(k)+u(k) d t \\
u(k+1)=u(k)+\frac{1}{M+\lambda_{11 f}+\lambda_{11 g}}\left(T_{\text {thurst }}+X_{F u u} u_{F}\left|u_{F}\right|+X_{G u u} u_{G}\left|u_{G}\right|\right) d t \\
z(k+1)=z(k)+w(k) d t \\
w(k+1)=w(k)+\frac{1}{M+\lambda_{33 f}+\lambda_{33 g}}\left(F_{W}+X_{F W W} w_{F}\left|w_{F}\right|+Z_{G w w} w_{G}\left|w_{G}\right|\right) d t
\end{array}\right.
$$

where $x, z, u$, and $w$ are the forward displacement, the vertical displacement, and the forward speed and vertical speed of the center of mass of the wave glide in the overall coordinate system, respectively; $M$ is the overall mass of the wave glider; $\lambda_{11 f}, \lambda_{11 g}$, $\lambda_{33 f}$, and $\lambda_{33 g}$ are the forward and vertical additional masses of the surface float and the submerged glider, respectively; $u_{F}$ and $u_{G}$ represent the forward speeds of the surface float and the submerged glider, respectively; $w_{F}$ and $w_{G}$ represent the vertical speeds of the surface float and the submerged glider, respectively [15]. The geometric parameters and hydrodynamic parameters of the "Black Pearl" wave glider are provided in Tables 1 and 2, respectively [16].

The forward thrust of the wave glider is generated by transforming the vertical motion of six pairs of hydrofoils into the forward motion of the submerged glider. Therefore, only its forward component force is considered in this paper. According to the empirical formula, the forward thrust can be expressed as

$$
T_{\text {thrust }}=\left[\left(0.5 \rho V^{2} S_{W} C_{L}\right) \sin (\alpha+\beta)\right]-\left[\left(0.5 \rho V^{2} S_{W} C_{D}\right) \cos (\alpha+\beta)\right]
$$

where $C_{L}$ and $C_{D}$ denote the lift coefficient and the drag coefficient of the hydrofoil, respectively, and their values can refer to the values of the wing plate of the underwater glider [17]; $\alpha$ represents the angle of attack; $\beta$ expresses the angle between the wing plate and the horizontal plane; $V$ is the upstream velocity; $S$ denotes the cross-sectional area of the hydrofoil; and $S_{W}$ denotes the projected area of the hydrofoil in the pulling direction of the umbilical cable. 


$$
S_{W}=S \cos \beta
$$

Table 1. Non-dynamic parameters of the "Black Pearl" wave glider.

\begin{tabular}{|c|c|c|c|}
\hline Parameter & Value & Unit & Description \\
\hline $\mathrm{m}_{\mathrm{F}}$ & 30 & $\mathrm{~kg}$ & Mass of the surface float \\
\hline $\mathrm{m}_{\mathrm{G}}$ & 30 & $\mathrm{~kg}$ & Mass of the submerged glider \\
\hline $\mathrm{m}_{\mathrm{B}}$ & 65 & $\mathrm{~kg}$ & Total mass of the wave glider \\
\hline $\mathrm{d}_{\mathrm{GB}}$ & 3.8 & $\mathrm{~m}$ & Distances between body frame center and submerged glider \\
\hline$d_{F B}$ & 3.8 & $\mathrm{~m}$ & Distances between body frame center and float mass center \\
\hline $\mathrm{D}_{\text {float }}$ & $1.6 \times 0.5 \times 0.18$ & $\mathrm{~m}^{3}$ & Float dimension \\
\hline $\mathrm{D}_{\text {glider }}$ & $1.8 \times 1.0 \times 0.30$ & $\mathrm{~m}^{3}$ & Submerged glider dimension \\
\hline$\Delta_{\text {float }}$ & 85 & $\mathrm{~kg}$ & Float maximum displacement \\
\hline$\Delta_{\text {glider }}$ & 12 & $\mathrm{~kg}$ & Submerged glider displacement \\
\hline $\mathrm{L}_{\mathrm{umb}}$ & 7 & $\mathrm{~m}$ & Length of the umbilical \\
\hline $\mathrm{g}$ & 9.8 & $\mathrm{~m} / \mathrm{s}^{2}$ & Gravity constant \\
\hline
\end{tabular}

Table 2. Dynamic parameters of the "Black Pearl" wave glider.

\begin{tabular}{cccc}
\hline Parameter & Value & Unit & Description \\
\hline$\lambda_{11 \mathrm{f}}$ & 43.5 & $\mathrm{~kg}$ & Forward added mass of the surface float \\
$\lambda_{11 \mathrm{~g}}$ & 65.1 & $\mathrm{~kg}$ & Vertical added mass of the surface float \\
$\lambda_{33 \mathrm{f}}$ & 16.4 & $\mathrm{~kg}$ & Forward added mass of the submerged glider \\
$\lambda_{33 \mathrm{~g}}$ & 82.3 & $\mathrm{~kg}$ & Vertical additional mass of the submerged glider \\
$\mathrm{X}_{\mathrm{Fuu}}$ & -42.3 & $\mathrm{~kg} / \mathrm{m}$ & Forward resistance coefficient of the surface float \\
$\mathrm{X}_{\mathrm{Fww}}$ & -18.4 & $\mathrm{~kg} / \mathrm{m}$ & Vertical resistance coefficient of the surface float \\
$\mathrm{Z}_{\mathrm{Guu}}$ & -87.6 & $\mathrm{~kg} / \mathrm{m}$ & Forward drag coefficient of the submerged glider \\
$\mathrm{Z}_{\mathrm{Gww}}$ & -270 & $\mathrm{~kg} / \mathrm{m}$ & Vertical resistance coefficient of the submerged glider \\
\hline
\end{tabular}

The SALL submerged glider is capable of effectively expanding the projected area of the hydrofoil in the pulling force direction of the umbilical cable, the hydrofoil and the umbilical cable can keep a relatively fixed angle to glide, and the hydrofoil can capture more wave energy in the vertical direction, as shown in Figure 8. $\alpha$ represents the angle of attack, $\beta$ represents the angle between the wing plate and the horizontal plane, $V$ represents the upstream velocity, $F_{k}$ represents the tension of the spring, $F_{L}$ represents the lift force of the hydrofoil, $F_{D}$ represents the drag force of the hydrofoil, and $F_{T}$ represents the pull of the attack of the umbilical cable.

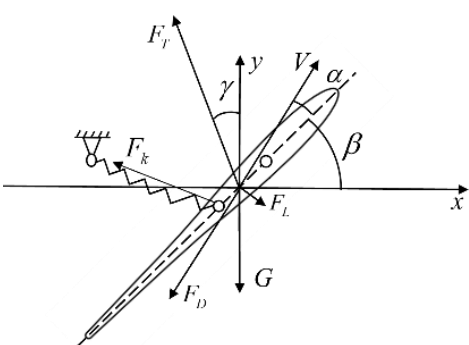

(a)

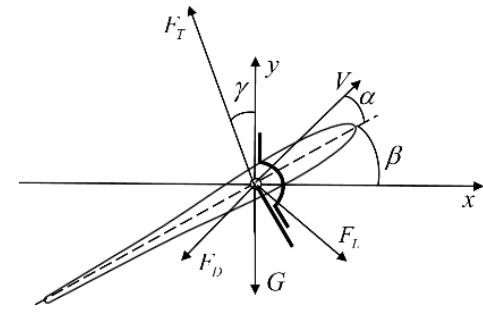

(b)

Figure 8. The force analysis of the hydrofoil during the ascent phase. (a) Conventional submerged glider; and (b) self-adjusting lower-limit submerged glider.

\section{Numerical Simulations}

In this paper, the commercial CFD software FLUENT was used to simulate the forward thrust of the two-dimensional (2D) hydrofoil, and the standard $k-\varepsilon$ turbulence model was adopted. The object of simulation was the "Black Pearl" wave glider. The NACA0012 was used as the simulation hydrofoil, and the hydrofoil wall was modified by using the equilibrium wall function. The main parameters of the hydrofoil are provided in Table 3 [18]. 
Table 3. Main parameters of the hydrofoil.

\begin{tabular}{ccc}
\hline Parameter & Value & Unit \\
\hline Chord length, $\mathrm{c}$ & 0.16 & $\mathrm{~m}$ \\
Hydrofoil thickness, $\mathrm{d}$ & 0.02 & $\mathrm{~m}$ \\
Hydrofoil shape & NACA0012 & $\mathrm{kg} / \mathrm{m}^{2}$ \\
Moment of inertia, $\mathrm{J}$ & 0.922 & $\mathrm{~m} / \mathrm{s}$ \\
Free stream velocity, $\mathrm{U}_{\infty}$ & 0.25 & $\mathrm{~m}$ \\
\hline Distance between shaft center and mass center & 0.04 &
\end{tabular}

\subsection{Simulation Grid Generation and Irrelevance Verification}

The hydrofoils of the submerged glider exist in pairs. The force condition of the hydrofoils on both sides are the same, and they are distributed in an equally spaced manner. Therefore, a pair of hydrofoils was selected as the research object. The 2D simulation was performed, and Figure 9 provides the definition of the boundary conditions. The chord length $\mathrm{c}$ of the hydrofoil was $0.16 \mathrm{~m}$, and the distance between the outlet and the hydrofoil should be greater than five times the chord length of the hydrofoil. The outlet condition at 10c downstream was set to a uniform static pressure to avoid non-physical reflection from the outlet. The inlet condition was set to uniform flow with a constant velocity, and the velocity was set to $0.25 \mathrm{~m} / \mathrm{s}$ in light of the average velocity of the "Black Pearl" wave glider. The unstructured grid was adopted as the global grid, and the boundary layer was 10 layers.

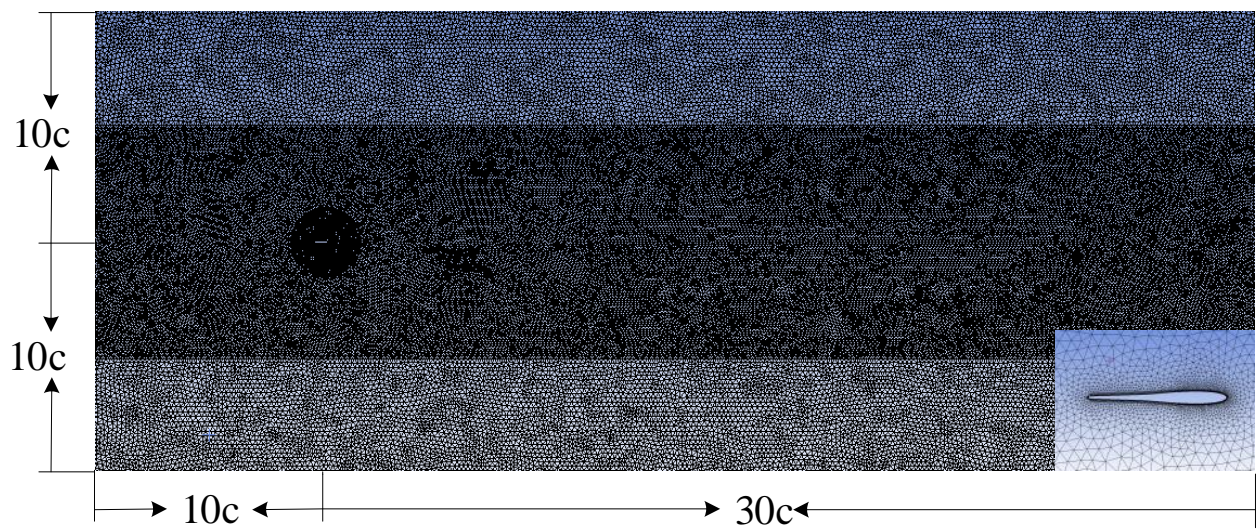

Figure 9. The definition of the boundary conditions.

The grid heigh $y^{+}$is a dimensionless number that is used to calculate the spacing of the first layer of grid. $y^{+}$can be expressed as

$$
y^{+}=\frac{\Delta y u_{r} \rho}{u}=\frac{\Delta y}{u} \sqrt{\frac{\tau_{w}}{\rho}}
$$

where $u$ represents the mean velocity of the fluid, $u_{r}$ represents the friction velocity of the wall, $\tau_{w}$ represents the shearing stress of the wall, and $\Delta y$ represents the height of the first grid.

The $k-\varepsilon$ model generally requires $y^{+}$in the range of 30-100. Thus, the grid height $y^{+}$ of the first layer was strictly limited to 60 in this paper.

The Reynolds-averaged Navier-Stokes (RANS) equation turbulence mode and the standard $k-\varepsilon$ model were selected for numerical simulation. The semi-implicit method for pressure linked equations (SIMPLE) algorithm was used for the pressure-velocity coupling. The second-order implicit scheme was used in the unsteady scheme. The absolute convergence criteria of $1 \mathrm{e}^{-3}$ were set for $x$ velocity, $y$ velocity, and continuity. In the simulation, user-defined functions (UDFs) were used to control the internal mesh movement [4]. 
To verify the feasibility of the grid, we compared the forward thrusts of a pair of hydrofoils with torsion spring stiffness coefficient of $4 \mathrm{~N} \cdot \mathrm{m} / \mathrm{rad}$ under grid1, grid2, grid3, grid4, grid5, and grid6 [19]. The numerical results of the different levels of cells are provided in Table 4.

Table 4. The numerical results of the different levels of cells.

\begin{tabular}{ccccc}
\hline Grid & Cells & K & Inflow Velocity & Average Thrust (N) \\
\hline Grid1 & 21,185 & $4 \mathrm{~N} \cdot \mathrm{m} / \mathrm{rad}$ & $0.25 \mathrm{~m} / \mathrm{s}$ & 4.55757 \\
Grid2 & 29,204 & $4 \mathrm{~N} \cdot \mathrm{m} / \mathrm{rad}$ & $0.25 \mathrm{~m} / \mathrm{s}$ & 4.64766 \\
Grid3 & 45,682 & $4 \mathrm{~N} \cdot \mathrm{m} / \mathrm{rad}$ & $0.25 \mathrm{~m} / \mathrm{s}$ & 4.66012 \\
Grid4 & 80,507 & $4 \mathrm{~N} \cdot \mathrm{m} / \mathrm{rad}$ & $0.25 \mathrm{~m} / \mathrm{s}$ & 4.87065 \\
Grid5 & 185,166 & $4 \mathrm{~N} \cdot \mathrm{m} / \mathrm{rad}$ & $0.25 \mathrm{~m} / \mathrm{s}$ & 4.91025 \\
Grid6 & 676,596 & $4 \mathrm{~N} \cdot \mathrm{m} / \mathrm{rad}$ & $0.25 \mathrm{~m} / \mathrm{s}$ & 4.92469 \\
\hline
\end{tabular}

The fluid density $\rho$ was set to $998.2 \mathrm{~kg} / \mathrm{m}^{-3}$, inflow velocity $v$ was set to $0.25 \mathrm{~m} / \mathrm{s}$, and the NACA0012 airfoil was adopted. The numerical results of the different levels of cells are given in Table 4, and the grid size was found to have little influence on the calculation accuracy. Considering the accuracy of calculation and the reasonable utilization of calculation resources, we used grid3 for the following simulation. In the simulation, the swing mode of the hydrofoil was adopted by the conventional submerged glider through the UDF.

To verify the effectiveness of the simulation, we carried out the forward thrust tank experiment of a pair of hydrofoils. The experimental device was composed of two mechanical cylinders. The piston travel and the frequency of the cylinder were able to be adjusted, as shown in Figure 10. The swing structure of the conventional submerged glider was adopted for the mechanism of the pair of hydrofoils in the experiment, which was identical to the above simulation experiment. The up and down strokes of the mechanical cylinder were set to $0.2 \mathrm{~m}$, and the movement time was set to $4 \mathrm{~s}$. The tank experiment on the pair of hydrofoils was the fixed-point test, for which there was no relative motion, and thus a counterweight was applied to simulate the water resistance caused by a flow rate of $0.25 \mathrm{~m} / \mathrm{s}$.
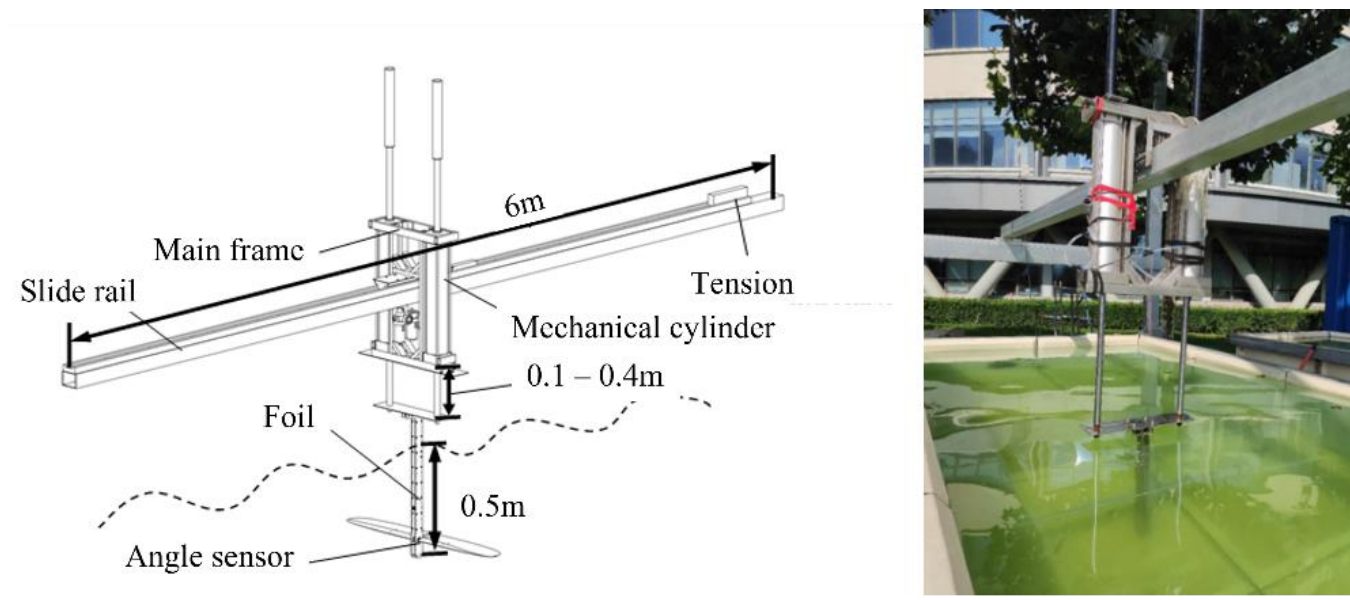

Figure 10. The experimental device.

The forward thrust of the pair of hydrofoils obtained by the experiment is shown in Figure 11. The wire rope connecting the sensor and the pair of hydrofoils was flexible, and thus there was no negative thrust in the forward thrust. 


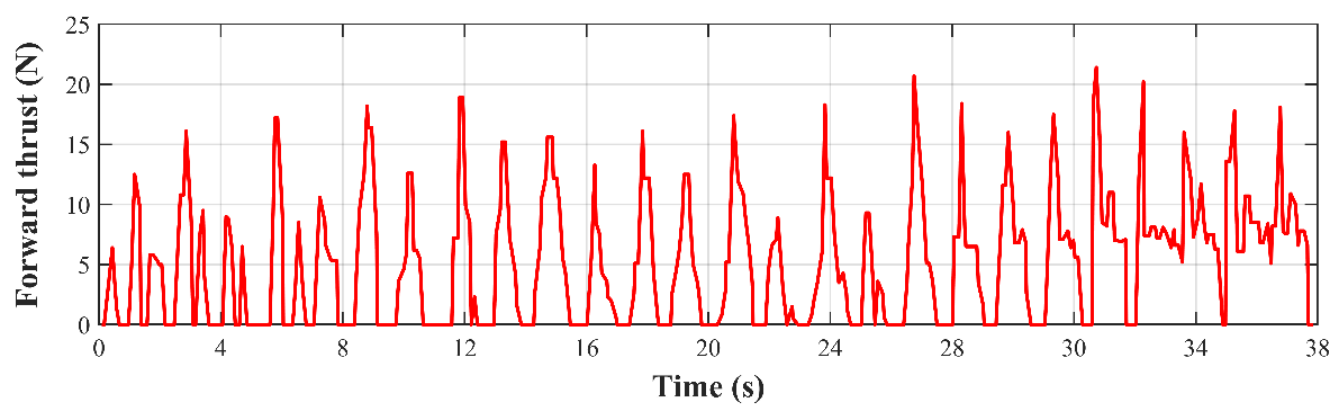

Figure 11. The forward thrust of the pair of hydrofoils obtained by the experiment.

The comparison of the tank experiment and numerical simulation is shown in Table 5 . There was no negative thrust in the tank experiment, and thus the average thrust in the tank experiment was higher than that in the numerical simulation. The peak thrust in the tank experiment was higher than that in the numerical simulation; however, the difference in average thrust was small. Thus, the data obtained in the numerical simulation are effective.

Table 5. The comparison of the tank experiment and numerical simulation results.

\begin{tabular}{cccc}
\hline Type & Maximum Thrust (N) & Minimum Thrust (N) & Average Thrust (N) \\
\hline Numerical simulation & 21.4 & 0 & 5.1575 \\
Tank experiment & 15.7 & -1.23 & 4.6601 \\
\hline
\end{tabular}

\subsection{Numerical Simulation of the Submerged Glider}

The complex and changeable marine environment increases the difficulty of systematic simulation. To simplify the simulation and find a quantitative relationship more intuitively, we used the second-level sea state of the eastern waters of Qingdao, China, as the input condition of the simulated wave. The wave height was $0.4 \mathrm{~m}$, and the wave period was $4 \mathrm{~s}$. The simulation time step was set to $0.001 \mathrm{~s}$, and every simulation was calculated for 20,000 steps. FLUENT was used to simulate the forward thrust of the conventional submerged glider under the different stiffness coefficients of tension spring. To unify the simulation variables and set the simulation parameters in the UDF expediently, we applied the torsion spring to the conventional submerged glider, which was equivalent to the effect of the tension spring in the UDF. The stiffness coefficient of the spring was equivalent to the stiffness coefficient of the torsion spring.

In the simulation, the SALL submerged glider and the conventional submerged glider had the same geometric dimensions. The motion direction in the $Y$-axis and the lower limit of hydrofoil swing of the SALL submerged glider were different from that of the conventional submerged glider, which can be set in the UDF. The geometrical details and the definition of the numerical simulations are given in Tables 6 and 7 .

Table 6. The geometric dimension of the SALL submerged glider and conventional submerged glider.

\begin{tabular}{cccc}
\hline Model & Overall Size (mm) & $\begin{array}{c}\text { Number of } \\
\text { Hydrofoils }\end{array}$ & $\begin{array}{c}\text { Size of } \\
\text { Hydrofoils (mm) }\end{array}$ \\
\hline SALL submerged glider & $325 \times 1093 \times 1884$ & 12 & $500 \times 160 \times 20$ \\
Conventional submerged glider & $325 \times 1093 \times 1884$ & 12 & $500 \times 160 \times 20$ \\
\hline
\end{tabular}

Table 7. The numerical simulations for the submerged glider.

\begin{tabular}{cccc}
\hline Simulated Model & $\boldsymbol{Y}$-Axis Speed & $\begin{array}{c}\text { The Angle of Movement } \\
\text { Direction and } \boldsymbol{Y} \text {-Axis }\end{array}$ & $\begin{array}{c}\text { Lower Limit of } \\
\text { Hydrofoil }\end{array}$ \\
\hline SALL submerged glider & $0.471 \times \sin (1.57 \mathrm{t})$ & $0^{\circ}$ & Follow-up \\
Conventional submerged glider & $0.471 \times \sin (1.57 \mathrm{t})$ & $10^{\circ}$ & Fixed \\
\hline
\end{tabular}


The stiffness coefficient of the torsion spring had a significant effect on the forward thrust of the conventional submerged glider, which is shown in Figure 12 . When the stiffness coefficient of the torsion spring was $2 \mathrm{~N} \cdot \mathrm{m} / \mathrm{rad}$, the hydrofoil generated a relatively obvious negative thrust.

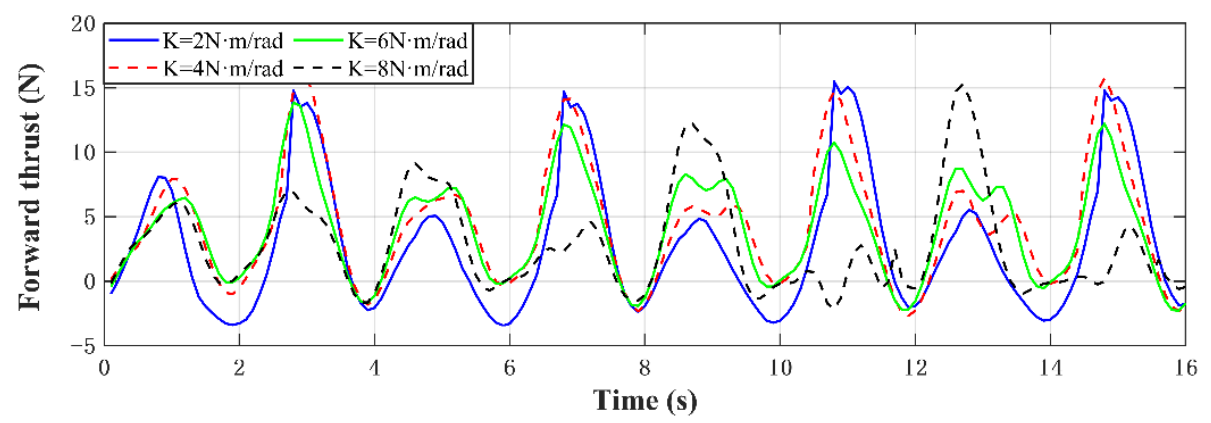

Figure 12. The forward thrusts of the conventional submerged glider under the different $\mathrm{K}$.

The pressure nephogram of the hydrofoil in a period is shown in Figure 13. The hydrofoil with torsion spring stiffness $\mathrm{K}=2 \mathrm{~N} \cdot \mathrm{m} / \mathrm{rad}$ generated less torque at $\mathrm{t} / \mathrm{T}=1$, which caused a small restoring moment of the hydrofoil. Thus, the hydrofoil cannot be returned to the horizontal state at this time.

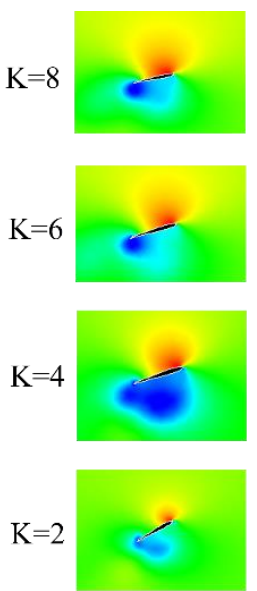

(a)

$\mathrm{t} / \mathrm{T}=0.25$
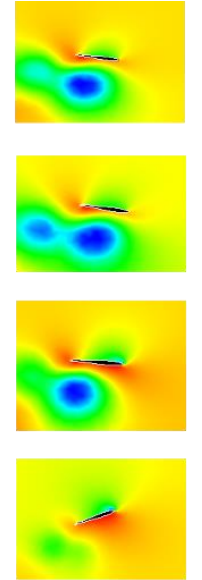

(b)

$\mathrm{t} / \mathrm{T}=0.5$
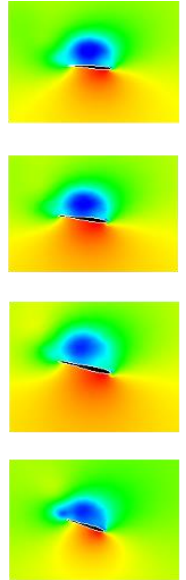

(c)

$\mathrm{t} / \mathrm{T}=0.75$
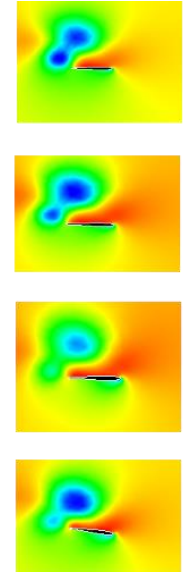

(d)

$\mathrm{t} / \mathrm{T}=1$

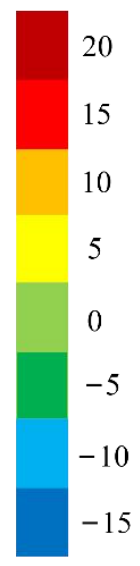

Figure 13. The pressure nephogram of the conventional submerged glider under the different $\mathrm{K}$ in a single cycle. (a) $\mathrm{t} / \mathrm{T}=0.25 ;(\mathbf{b}) \mathrm{t} / \mathrm{T}=0.5 ;(\mathbf{c}) \mathrm{t} / \mathrm{T}=0.75 ;$ and $(\mathbf{d}) \mathrm{t} / \mathrm{T}=1$.

The hydrodynamic moment generated by the vertical ascent made the hydrofoil swing downward continually in the next period, and thus negative thrust was generated. When the stiffness coefficients of the torsion spring were $\mathrm{K}=4 \mathrm{~N} \cdot \mathrm{m} / \mathrm{rad}, \mathrm{K}=6 \mathrm{~N} \cdot \mathrm{m} / \mathrm{rad}$, and $\mathrm{K}=8 \mathrm{~N} \cdot \mathrm{m} / \mathrm{rad}$, the hydrofoil was essentially horizontal at $\mathrm{t} / \mathrm{T}=1$, and no negative thrust was generated.

The average forward thrust of the conventional submerged glider is shown in Figure 14. The following conclusions can be drawn from Figures 12 and 14 . When $\mathrm{K}=2 \mathrm{~N} \cdot \mathrm{m} / \mathrm{rad}$, the peak thrust of the submerged glider was larger. Due to a large negative thrust that was generated at this time, the average thrust was small. When $\mathrm{K}=4 \mathrm{~N} \cdot \mathrm{m} / \mathrm{rad}$, the average forward thrust was essentially consistent with that when $\mathrm{K}=2 \mathrm{~N} \cdot \mathrm{m} / \mathrm{rad}$. There was no negative thrust to generate under $\mathrm{K}=4 \mathrm{~N} \cdot \mathrm{m} / \mathrm{rad}$, and therefore the average forward thrust was the largest. Under $\mathrm{K}=6 \mathrm{~N} \cdot \mathrm{m} / \mathrm{rad}$ and $\mathrm{K}=8 \mathrm{~N} \cdot \mathrm{m} / \mathrm{rad}$, although no negative thrust was generated, the peak thrust of the submerged glider started to decrease, and the average thrust decreased. 


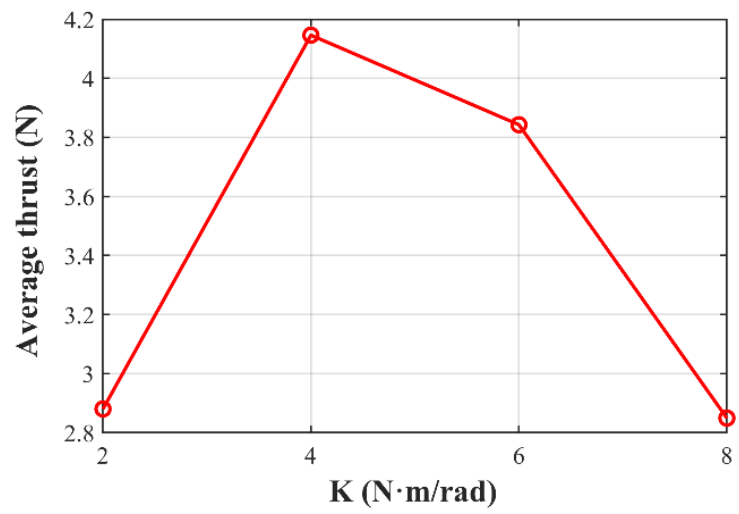

Figure 14. The average forward thrust of the conventional submerged glider under the different $\mathrm{K}$.

The stiffness coefficient of the torsion spring had a significant effect on the swing amplitude of the hydrofoil. With the increase of the torsion spring stiffness coefficient, the swing amplitude of the hydrofoil gradually decreased, as shown in Figure 15. When $\mathrm{K}=2$, the amplitude of the downward swing motion of the hydrofoil was close to $40^{\circ}$. When $\mathrm{K}=8$, the amplitude of the downward swing of the hydrofoil was only about $20^{\circ}$. When the swing was swung upward, the upper swing angle of the hydrofoil was limited to $20^{\circ}$, and therefore the limit angle of $20^{\circ}$ was set in the UDF under the different stiffness coefficients of the torsion spring.

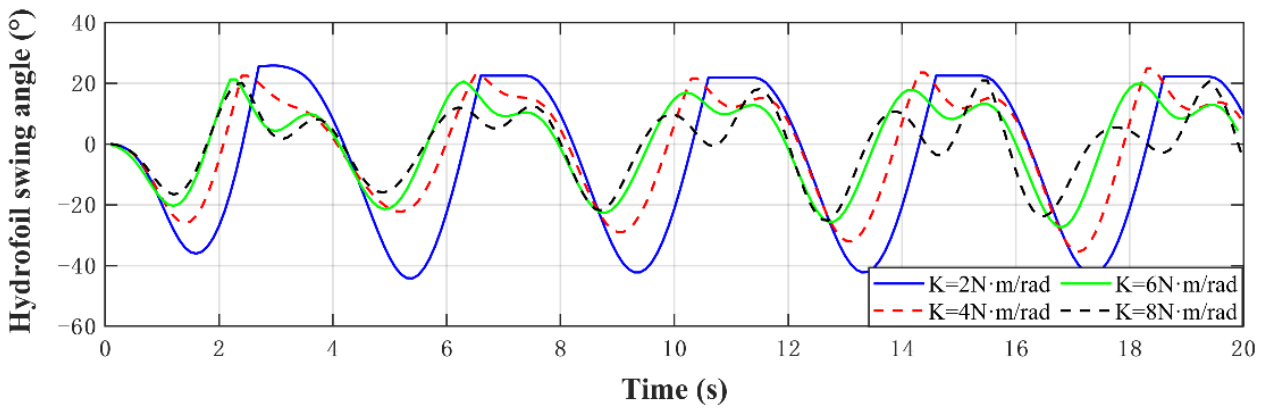

Figure 15. The swing angles of the hydrofoil for the conventional submerged glider under the different K.

\subsection{Numerical Simulation of the SALL Submerged Glider}

The same conditions were adopted for the numerical simulation of the SALL submerged glider. The forward thrusts of the SALL submerged glider under the different $\mathrm{K}$ and $\lambda$ are shown in Figure 16, wherein the CSG is an abbreviation of the conventional submerged glider.

The stiffness coefficient of the torsion spring also had a significant impact on the forward thrust of the SALL submerged glider. It can be seen from Figure 16 that the forward thrust of the SALL submerged glider displayed a large peak and a small peak in a period. The large peak of the forward thrust represents the steady down state of the submerged glider, and the small peak is the rising stage of the submerged glider. When $\mathrm{K}=2$, the two peaks of the thrust of the SALL submerged glider were roughly consistent with that of the CSG in a period. When $\lambda=10^{\circ}$, the large peak thrust of the submerged glider was slightly higher than that of the CSG. When $K=4$, the small peak thrust of the SALL submerged glider was more obviously improved than that of the CSG, which was caused by the SALL mechanism. The large peak thrust of the SALL submerged glider was also slightly higher than that of the CSG. The SALL mechanism limited the downward swing amplitude of the hydrofoil and shortened the motion time of the hydrofoil from the lower limit position to the horizontal middle position, and thus the response of the hydrofoil can be increased and the time that the hydrofoil stays at a fixed gliding angle of 
$20^{\circ}$ during the steady drop state can also be increased. When $\mathrm{K}=6$ and $\mathrm{K}=8$, the small peak thrust of the SALL submerged glider in a period was also higher than that of the CSG. In addition, the forward thrust of the SALL submerged glider was obviously improved at the rising stage of the hydrofoil.

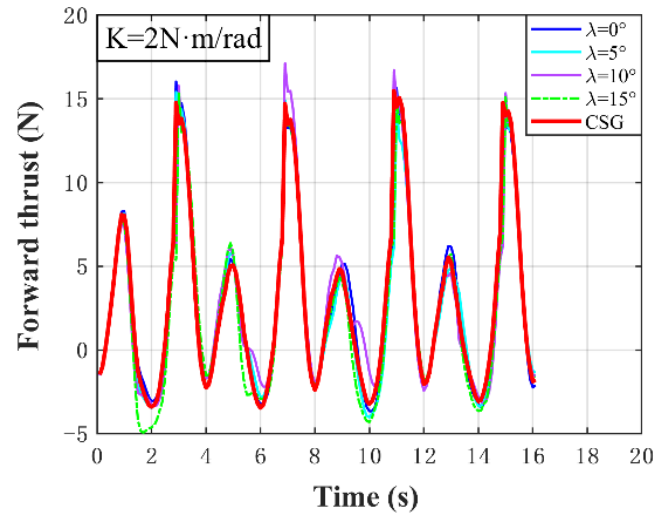

(a)

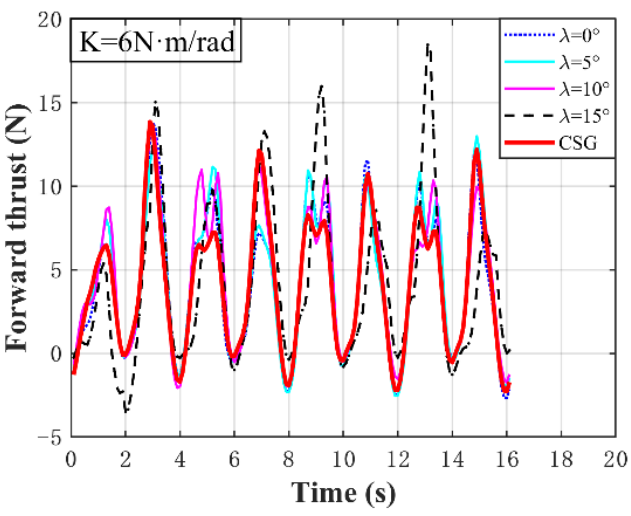

(c)

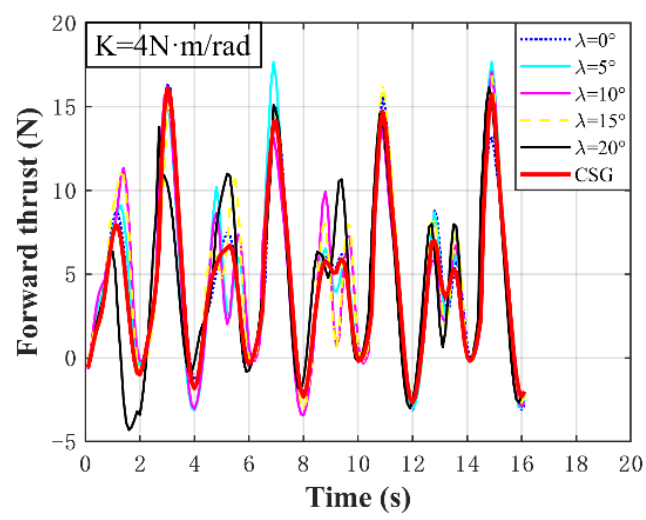

(b)

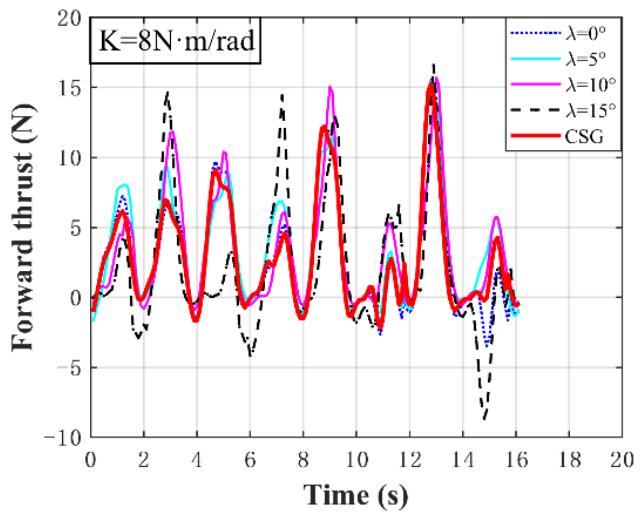

(d)

Figure 16. The forward thrusts of the SALL submerged glider under the different $K$ and $\lambda$. (a) Forward thrust under $\mathrm{k}=2$; (b) forward thrust under $\mathrm{k}=4$; (c) forward thrust under $\mathrm{k}=6$; and (d) forward thrust under $\mathrm{k}=8$.

The maximum average thrusts of a pair of hydrofoils with the SALL mechanism were $2.923 \mathrm{~N}, 4.883 \mathrm{~N}, 4.414 \mathrm{~N}$, and $3.350 \mathrm{~N}$ under $\mathrm{K}=2, \mathrm{~K}=4, \mathrm{~K}=6$, and $\mathrm{K}=8$, respectively, while the average forward thrusts of a pair of hydrofoils of the conventional submerged glider were $2.880 \mathrm{~N}, 4.146 \mathrm{~N}, 4.109 \mathrm{~N}$, and $2.849 \mathrm{~N}$, respectively. The average forward thrusts of the submerged glider and the relative difference values are given in Table 8. Compared with the conventional submerged glider, the forward thrusts of the SALL submerged glider had a significant improvement. The average thrust change rates of the SALL submerged glider are given in Table 9.

Table 8. The average thrusts of the SALL submerged glider and conventional submerged glider under the different $\mathrm{K}$.

\begin{tabular}{cccccc}
\hline \multirow{2}{*}{$\begin{array}{c}\text { Stiffness } \\
\text { Coefficient }\end{array}$} & \multirow{2}{*}{$\begin{array}{c}\text { The Thrust of the Conventional } \\
\text { Submerged Glider (N) }\end{array}$} & \multicolumn{4}{c}{ The Thrust of the SALL Submerged Glider (N) } \\
\cline { 3 - 5 } & & $\boldsymbol{\lambda}=\mathbf{0}$ & $\boldsymbol{\lambda}=\mathbf{5}$ & $\boldsymbol{\lambda}=\mathbf{1 0}$ & $\boldsymbol{\lambda}=\mathbf{1 5}$ \\
\hline $\mathrm{K}=2$ & 2.880 & 2.797 & 2.638 & 2.923 & 2.284 \\
$\mathrm{~K}=4$ & 4.146 & 4.498 & 4.620 & 4.561 & 4.883 \\
$\mathrm{~K}=6$ & 4.109 & 4.067 & 4.259 & 4.414 & 4.144 \\
$\mathrm{~K}=8$ & 2.849 & 2.793 & 3.427 & 3.350 & 2.295 \\
\hline
\end{tabular}


Table 9. The average thrust change rates of the SALL submerged glider under the different $K$ and $\lambda$.

\begin{tabular}{cccccc}
\hline \multirow{2}{*}{$\begin{array}{c}\text { Stiffness } \\
\text { Coefficient }\end{array}$} & \multirow{2}{*}{$\begin{array}{c}\text { The Thrust of the Conventional } \\
\text { Submerged Glider (N) }\end{array}$} & \multicolumn{3}{c}{ The Change Rate of Average Thrust } \\
\cline { 3 - 6 } & 2.880 & $\boldsymbol{\lambda}=\mathbf{0}$ & $\boldsymbol{\lambda}=\mathbf{5}$ & $\boldsymbol{\lambda}=\mathbf{1 0}$ & $\boldsymbol{\lambda}=\mathbf{1 5}$ \\
\hline $\mathrm{K}=2$ & 4.146 & $-2.88 \%$ & $-8.40 \%$ & $1.50 \%$ & $-20.70 \%$ \\
$\mathrm{~K}=4$ & 4.109 & $8.50 \%$ & $11.43 \%$ & $10.01 \%$ & $17.78 \%$ \\
$\mathrm{~K}=6$ & 2.849 & $-1.02 \%$ & $3.65 \%$ & $7.42 \%$ & $0.85 \%$ \\
$\mathrm{~K}=8$ & $-1.97 \%$ & $20.70 \%$ & $20.29 \%$ & $-19.45 \%$ \\
\hline
\end{tabular}

The follow-up angle determined the average peak thrust; with the increase of the torsion spring stiffness coefficient, the follow-up angle corresponding to the average peak thrust decreased, as shown in Figure 17.

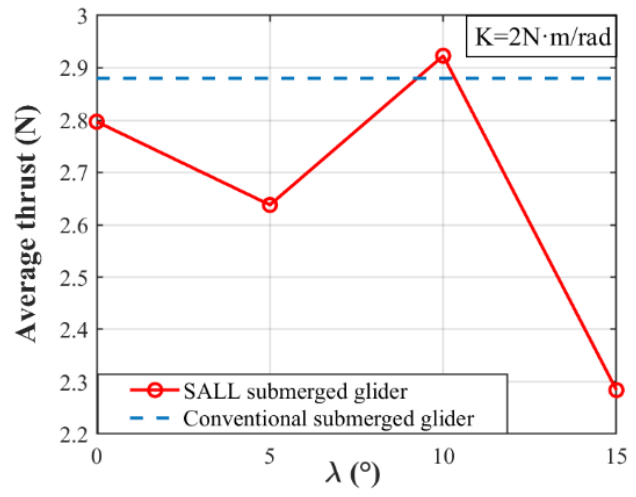

(a)

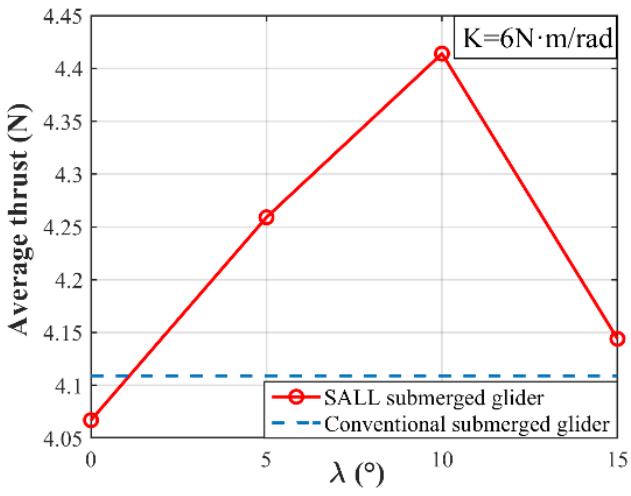

(c)

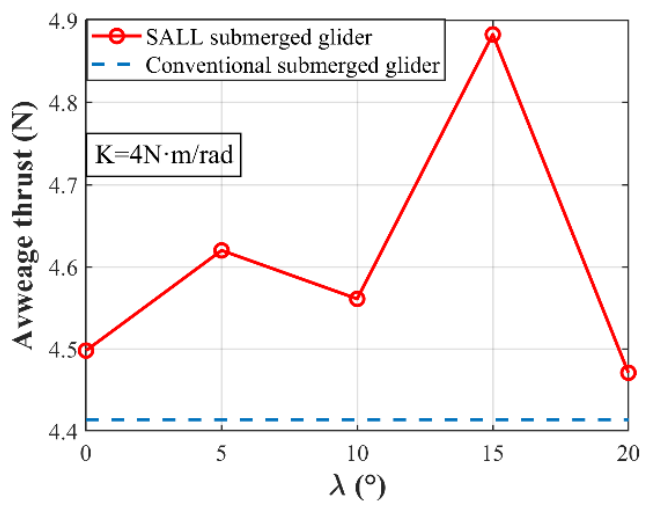

(b)

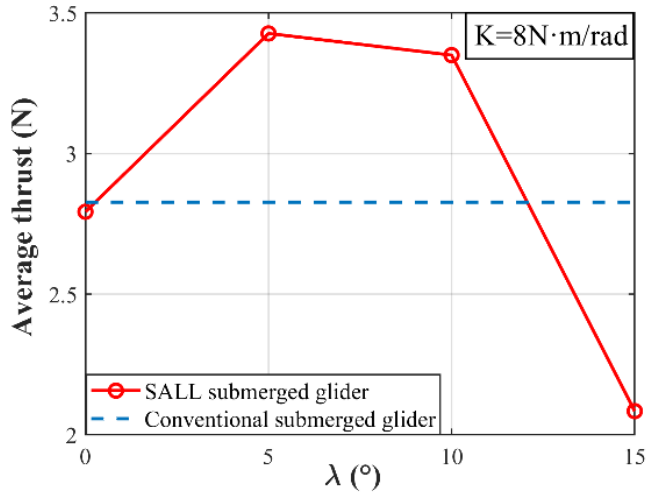

(d)

Figure 17. The average thrusts of the SALL submerged glider and the conventional submerged glider under the different K. (a) Average forward thrust under $\mathrm{k}=2$; (b) average forward thrust under $\mathrm{k}=4$; (c) average forward thrust under $k=6$; and (d) average forward thrust under $\mathrm{k}=8$.

\section{Tank Experiment and Sea Trial Verification}

Tank experiments were carried out to verify the propulsive performance of the SALL submerged glider, and a sea trial was carried out under real sea conditions.

\subsection{The Design of the SALL Submerged Glider}

The principal prototype of the SALL submerged glider was designed by improving the submerged glider of the conventional "Black Pearl" wave glider, as shown in Figures 18 and 19. A parallelogram mechanism was added onto the conventional submerged glider. The four sides of the parallelogram mechanism were in essence composed of the connecting link, metal connecting piece, fixed frame, and umbilical cable connector, and the joints of each side were connected by hinges, as shown in Figure 18a; the parallelogram mechanism is shown in the box of yellow lines in Figure 18c. The torsion spring 
clamp was made up of 316 stainless steel, and its inside was machined with limit holes. It was used to fix the upper arm of the torsion spring. The upper arm of torsion spring was clamped in different limit holes that were able to adjust the installation angle of the torsion spring (i.e., the follow-up angle), as shown in the Figure 18b. The limit rod was rigidly connected with the pivot. There was no relative movement between the limit rod and the pivot, and the hydrofoil was connected with the pivot through bolts. Therefore, the swing of the hydrofoil can be limited through the limit rod. In the actual test, the change of umbilical cable inclination angle drove the swing of the umbilical cable connector, and the swing of the umbilical connector drove the connecting link to move back and forth. When the umbilical cable connector swung to the left, the connecting link moved to the right. When the umbilical cable connector swung to the right, the connecting link moved to the left, driving the metal connecting piece to swing, as shown in Figure 18c. The torsion spring fixed on the metal connecting piece also swung. The limit rod controlled the lower swing limit of the hydrofoil by colliding with the torsion spring.

Therefore, the lower swing limit of the hydrofoil can be varied with the change of the inclination angle of the umbilical cable, and the lower swing limit position of the hydrofoil can be adjusted by changing the installation angle of the torsion spring.

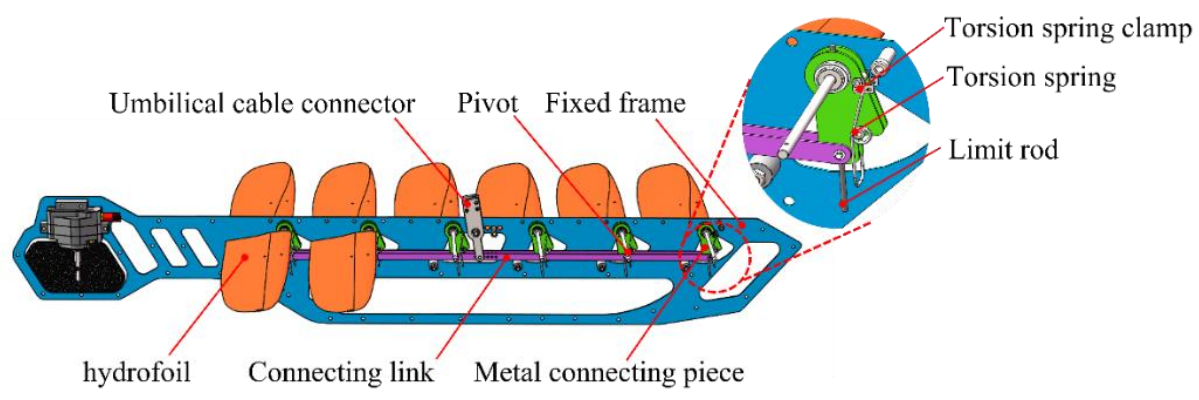

(a)

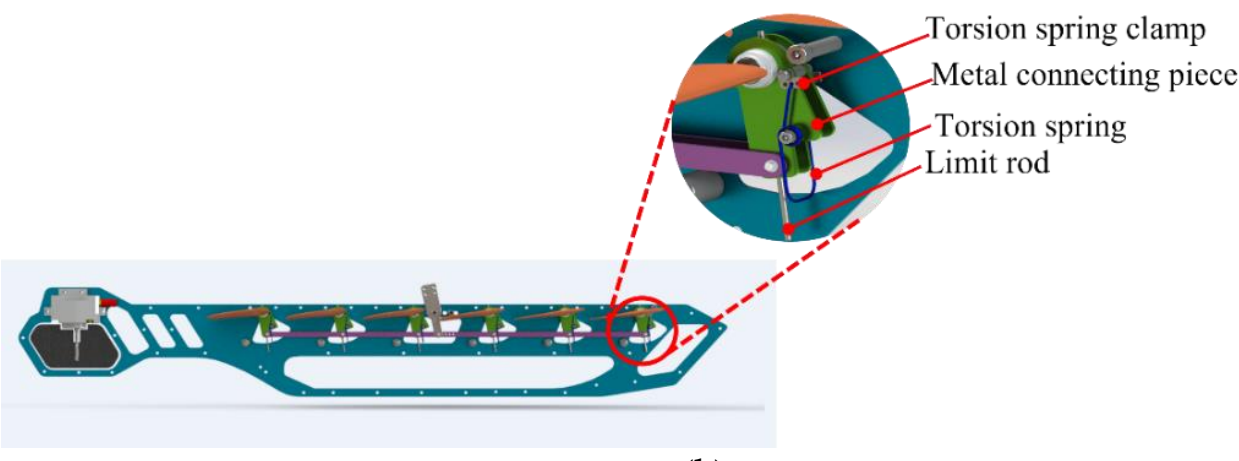

(b)

Parallelogram mechanism

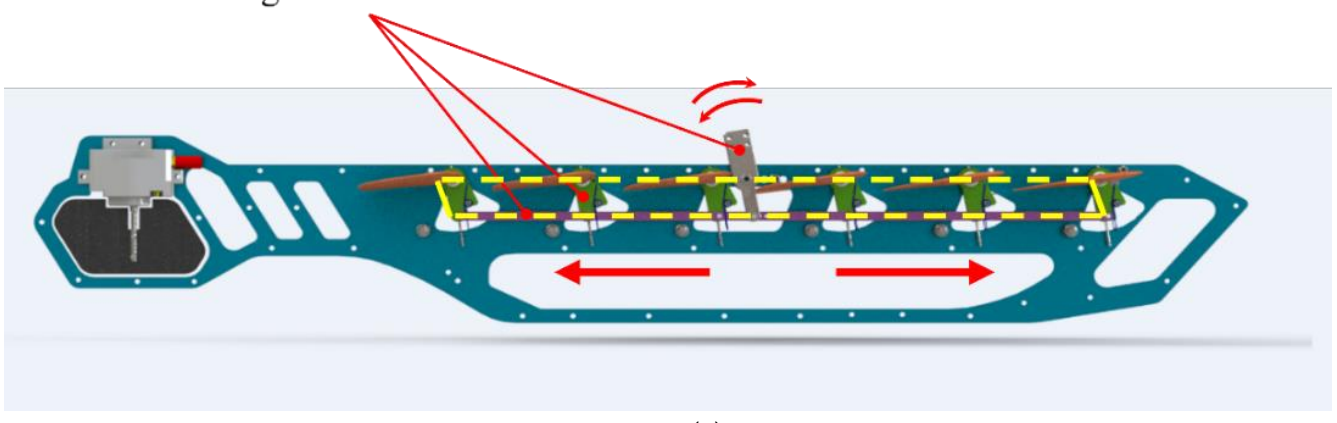

(c)

Figure 18. The structure of the SALL submerged glider. (a) The installation diagram of the torsion spring; (b) the internal structure diagram; and (c) the parallelogram mechanism. 


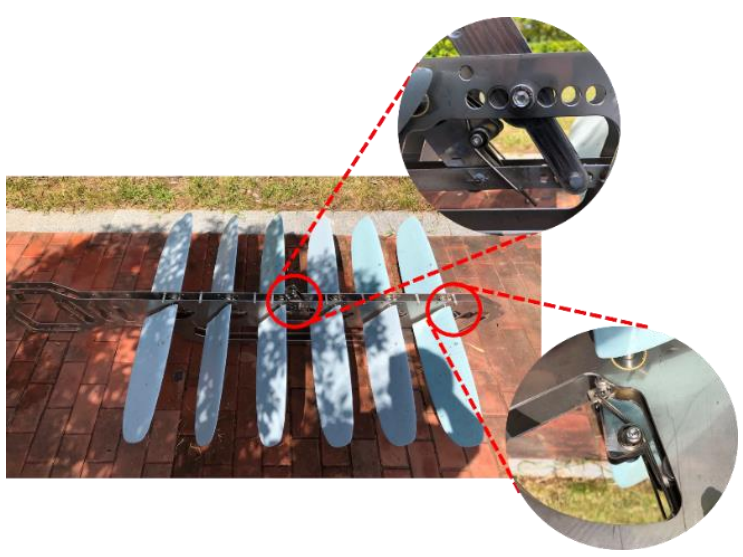

Figure 19. The physical prototype of the SALL submerged glider.

\subsection{Experimental Platform Setup}

To simulate real sea states as much as possible on land, we built a large-scale wave simulation platform to verify the propulsive performance of the submerged glider.

A crank rocker mechanism was designed, and the length of the crank was able to be adjusted by changing the lifting point position to simulate different wave heights. The speed of the alternating current electric machinery can be regulated with a frequency converter, and different wave periods can be simulated [20], as shown in Figure 20. A tension sensor made by the Bang YES precision measuring instrument (Shanghai, China) Co., Ltd. was installed on the slide rail to measure the forward thrust of the submerged glider, and three 3-axis attitude sensors made by the WitMotion ShenZhen (Shenzhen, China) Co., Ltd. were fixed on the submerged glider to measure the pitch angle of the submerged glider, the swing angle of the hydrofoil, and the inclination angle of the umbilical cable, as shown in Figure 21. The dimensions of the tank and the experimental platform are provided in Table 10, and the photos of the tank and the experimental platform are shown in Figure 22. The parameters of the tension sensor and the 3-axis attitude sensor are provided in Tables 11 and 12.

Table 10. The dimensions of the tank and experimental platform.

\begin{tabular}{cccc}
\hline Dimension & Tank & Experimental Platform & Unit \\
\hline Length & 6000 & 1884 & $\mathrm{~mm}$ \\
Width & 2000 & 1093 & $\mathrm{~mm}$ \\
Height & 1000 & 325 & $\mathrm{~mm}$ \\
\hline
\end{tabular}

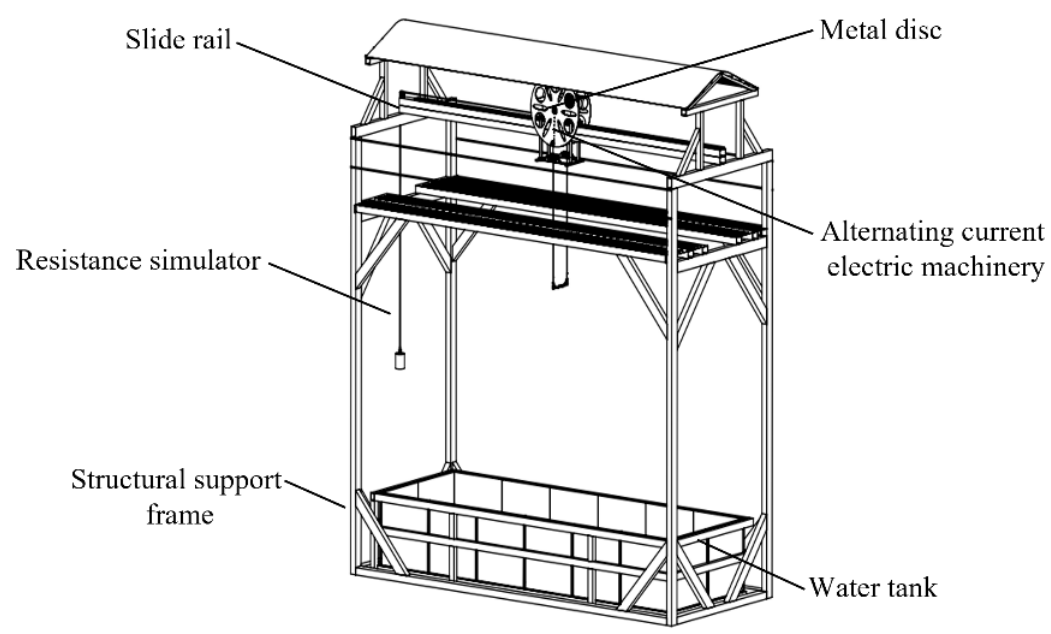

Figure 20. The large-scale wave simulation experiment platform. 


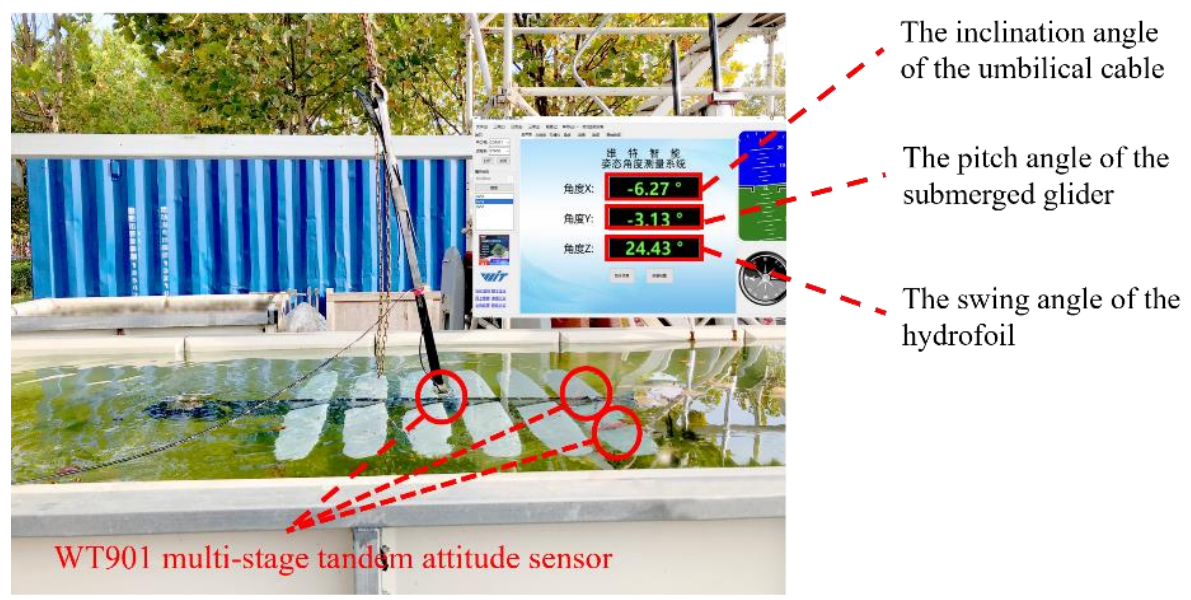

Figure 21. The SALL submerged glider in the tank experiment.
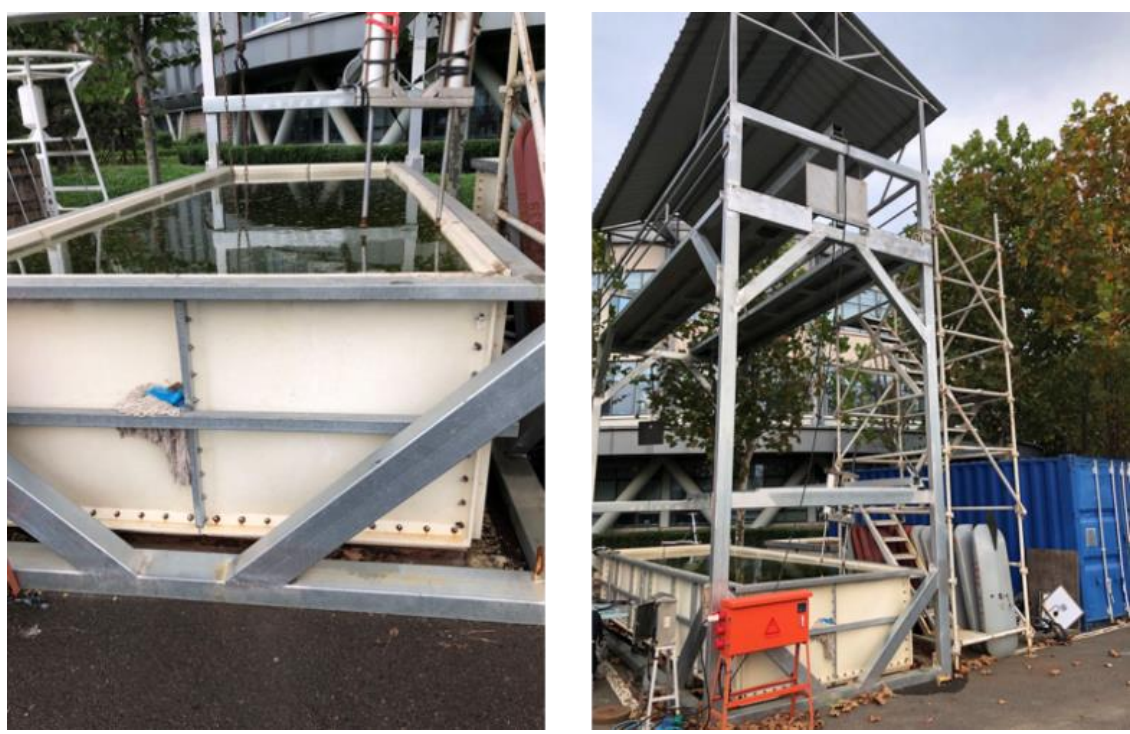

Figure 22. The photos of the tank and experimental platform.

Table 11. The parameters of the tension sensor.

\begin{tabular}{ccccc}
\hline Model & Range (N) & Resolution (N) & Accuracy & Communication Interface \\
\hline HF-500 & 500 & 0.1 & $0.5 \%$ & RS232 \\
\hline
\end{tabular}

Table 12. The parameters of the 3-axis attitude sensor.

\begin{tabular}{ccccc}
\hline Model & $\begin{array}{c}\text { Communication } \\
\text { Protocol }\end{array}$ & Baud Rate & $\begin{array}{c}\text { Transmission } \\
\text { Frequency }\end{array}$ & $\begin{array}{c}\text { Transmission } \\
\text { Distance }\end{array}$ \\
\hline WT901C485 & Modbus & $4800 \sim 921,600 \mathrm{bps}$ & $200 \mathrm{~Hz}(\mathrm{Max})$ & $10 \mathrm{~m}$ \\
\hline
\end{tabular}

\subsection{Tank Experiments}

The lifting point, the speed of the motor, wave height, and wave period were set to $0.2 \mathrm{~m}, 0.25 \mathrm{r} / \mathrm{s}, 0.4 \mathrm{~m}$, and $4 \mathrm{~s}$, respectively. The forward thrusts of the conventional submerged glider and the SALL submerged glider under tank experiments are shown in Figure 23. Because the conventional submerged glider was equipped with a spring device, the forward thrust of the submerged glider was uniform in ascending and dropping stages. Therefore, there was no large peak thrust and small peak thrust in a period. The SALL submerged glider was not equipped with a spring device, the forward thrust displayed 
an obvious shape of the spike, and large and small peak thrusts also appeared. Although the forward peak thrust of the SALL submerged glider was remarkably high, the duration time of the peak thrust was short, and the peak thrust was able to reach a maximum when the follow-up angle $\lambda$ was equal to $5^{\circ}$.

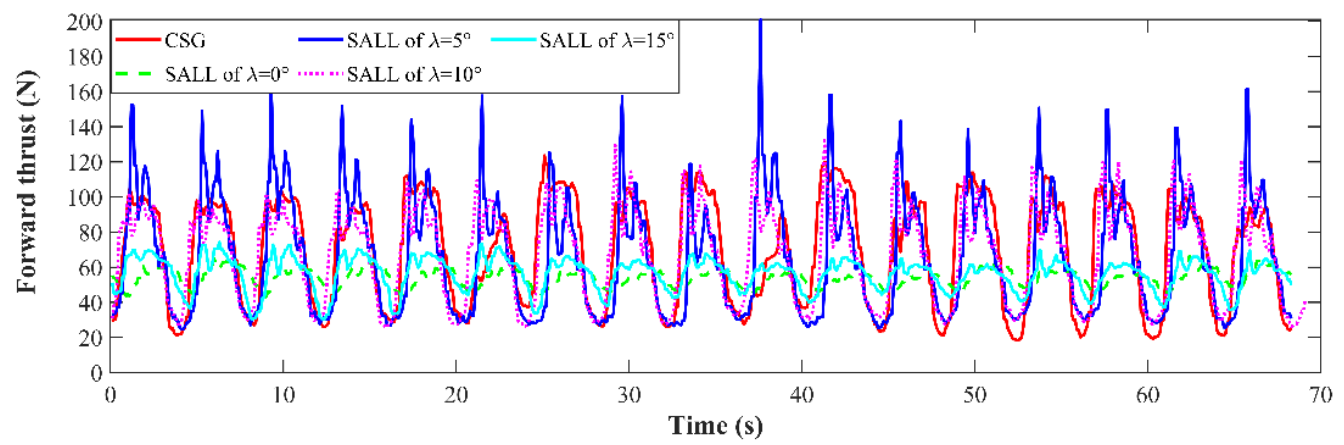

Figure 23. The forward thrusts of the conventional submerged glider and SALL submerged glider under tank experiments.

The attitude angle of the SALL submerged glider is shown in Figure 24. A relatively obvious follow-up effect of the umbilical cable inclination angle and the swing angle of the hydrofoil are shown in the fixed-point test of the tank experiment. With the increase of the umbilical cable inclination angle, the swing angle of the hydrofoil can be elevated, and with a decrease of the umbilical cable inclination angle, the swing angle of the hydrofoil can be reduced. Tank experiments under the conventional submerged glider and the SALL submerged glider are shown in Figure 25.

When the hydrofoil swung upward, the swing angle was positive. When it swung downward, the swing angle was negative. It can be seen from Figure 25a that the swing angle amplitude of the hydrofoil of the conventional submerged glider appeared at an obvious peak state when it swung downward. The swing angle amplitude of the hydrofoil of the SALL submerged glider was relatively gentle when it swung downward. The lower limit of the hydrofoil was adjusted along with the change of umbilical cable inclination angle, which showed that there was an obvious lower limit following effect. Figure $25 \mathrm{~b}$ provides the attitude of the SALL submerged glider in the non-fixed-point tank experiment, and the change of the lower limit of the hydrofoil was consistent with the change of cable inclination angle, which indicated that the angle difference of the lower limit of the hydrofoil and the umbilical cable was a relatively fixed value. Figure 25 c shows the attitude of the conventional submerged glider in the non-fixed-point tank experiment. Since the SALL mechanism was not installed on the conventional submerged glider, it can be seen that there was no relationship between the umbilical cable inclination angle and the swing angle of the hydrofoil.

The forward thrusts of the conventional submerged glider and the SALL submerged glider were quite different in the tank experiments. The forward peak thrust of the SALL submerged glider was high, and it can only be kept for a short period of time. The forward peak thrust of the conventional submerged glider was low, and it can be kept for a long period of time. When the conventional submerged glider was in the tank experiment, the spring force acted on the whole process of the hydrofoil to swing up and down, and thus the conventional submerged glider showed a continuous and stable low peak thrust. The SALL submerged glider only applied a torsion spring at the lower limit of the hydrofoil in the tank experiment. When the hydrofoil swung downward, there was only a short elastic impact on the torsion spring, and therefore there was a momentary peak thrust. 


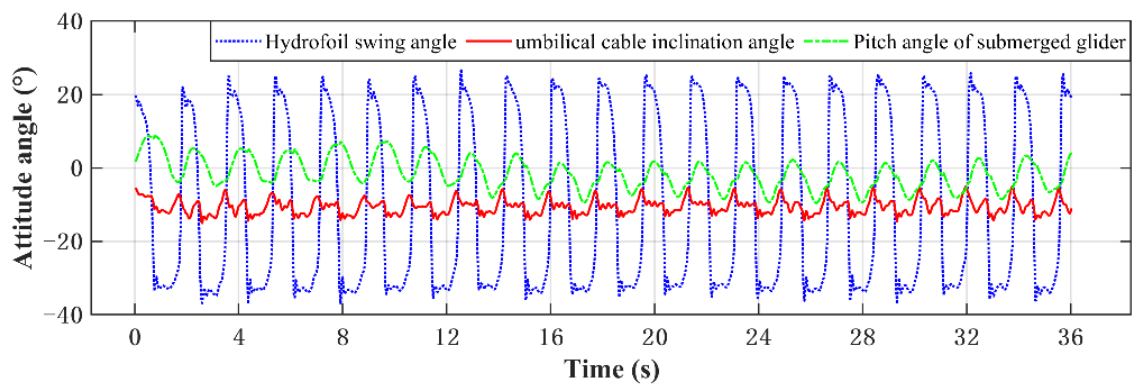

Figure 24. The attitude angle comparative experiment of the SALL submerged glider.

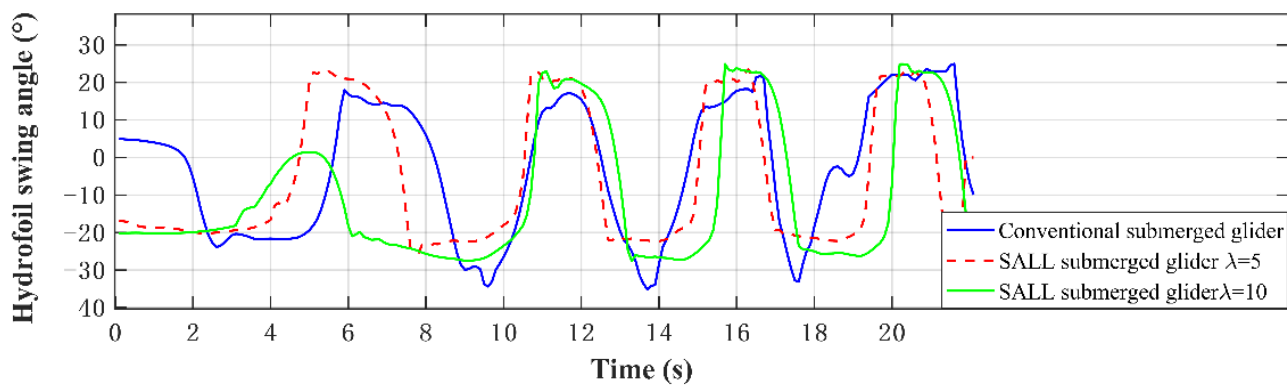

(a)

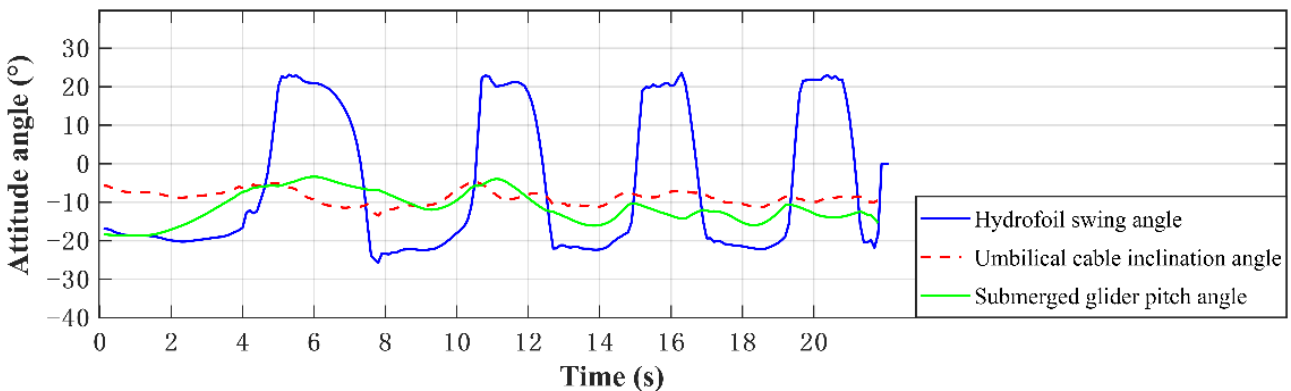

(b)

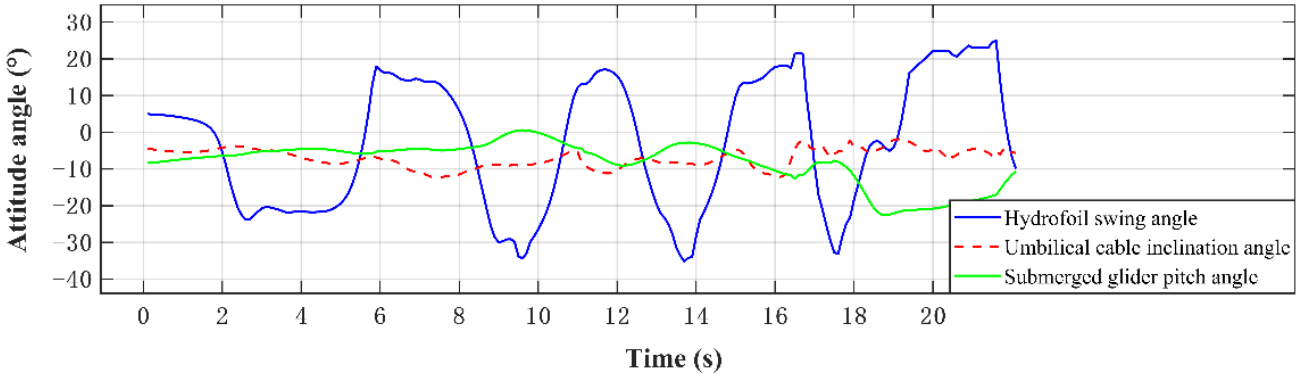

(c)

Figure 25. Tank experiments under the conventional submerged glider and the SALL submerged glider. (a) The swing angle comparisons of the conventional and the SALL submerged gliders; (b) the attitude angle of the SALL submerged glider; and (c) the attitude angle of the conventional submerged glider.

The momentum formula was introduced to compare the propulsive performance of the SALL and conventional submerged gliders, which can be expressed as

$$
F \Delta t=m \Delta v
$$

where $F$ represents the force acting on an object, $\Delta t$ represents the change of time, $\Delta v$ represents the change of the object velocity, and $m$ represents the mass of the object. 
It can be well known from the theorem of momentum that the change of the object velocity with large momentum in unit time was greater, and the object was able to better keep the movement trend. The integral areas of the thrusts of the conventional submerged glider and the SALL submerged glider in four random cycles are provided in Figures 26 and 27, respectively.

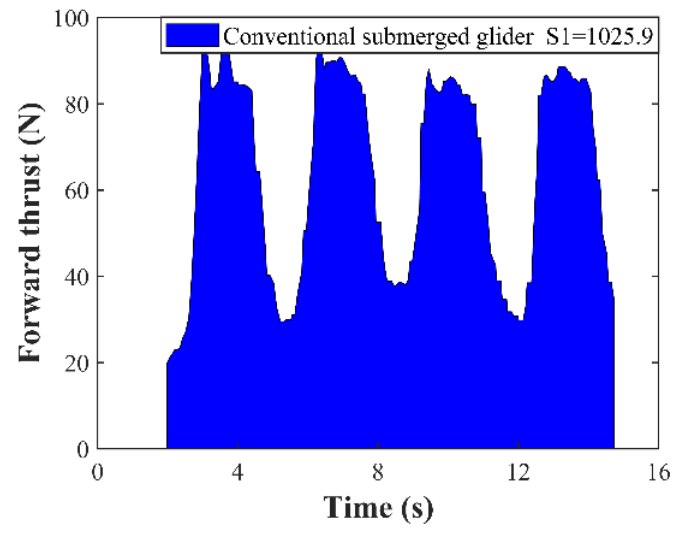

Figure 26. The integral area of the forward thrust of the conventional submerged glider in four random cycles.

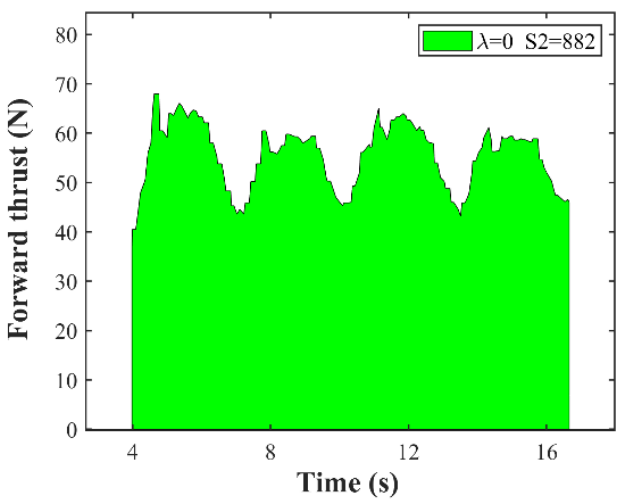

(a)

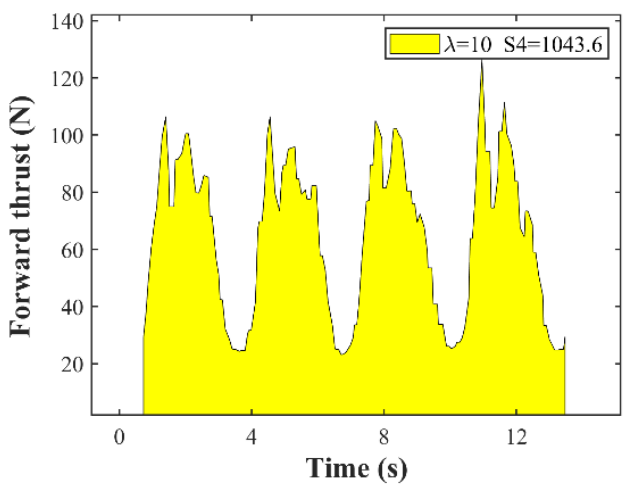

(c)

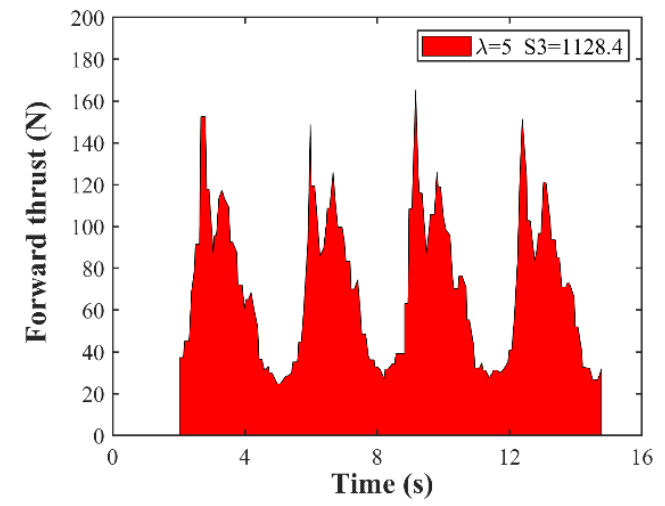

(b)

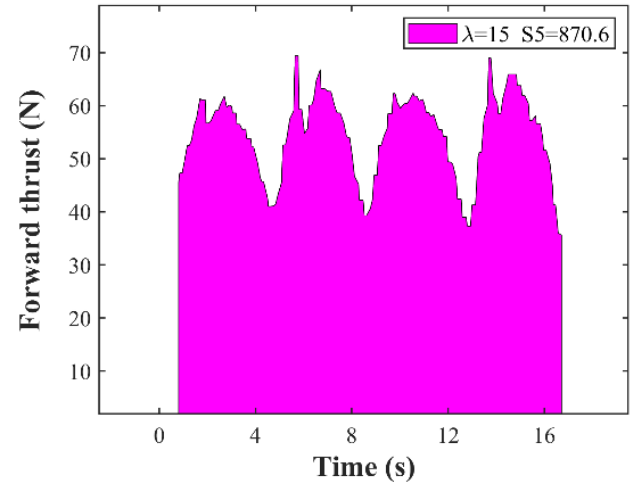

(d)

Figure 27. The integral area of the thrust of the SALL submerged glider in four random cycles. (a) The integral area at $\lambda=0^{\circ} ;(\mathbf{b})$ the integral area at $\lambda=5^{\circ} ;(\mathbf{c})$ the integral area at $\lambda=10^{\circ}$; and (d) the integral area at $\lambda=15^{\circ}$.

It can be seen from Figures 26 and 27 that four periods with relatively uniform peak thrusts were randomly selected from the thrust data of the conventional submerged glider and the SALL submerged glider, respectively, to integrate the area. The integral result of the conventional submerged glider was $S 1=1025.9$, and the solution results of the SALL 
submerged glider were S2 $=882, \mathrm{~S} 3=1128.4, \mathrm{~S} 4=1043.6$, and S5 $=870.6$ under $\lambda=0^{\circ}$, $\lambda=5^{\circ}, \lambda=10^{\circ}$, and $\lambda=15^{\circ}$, respectively. The integral areas of the SALL submerged glider were $9.99 \%$ and $1.73 \%$ under $\lambda=5^{\circ}$ and $\lambda=10^{\circ}$, respectively, higher than that of the conventional submerged glider. However, the integral areas of the SALL submerged glider were lower than that of the conventional submerged glider under $\lambda=0^{\circ}$ and $\lambda=15^{\circ}$.

In the tank experiment, the stiffness coefficient of the torsion spring was $K=8$. The average forward thrust of the simulation and the integral area of the random four periods of the tank experiment were in essence similar under $\mathrm{K}=8$, and the forward peak thrusts of the two groups of experiments were both determined at $\lambda=5^{\circ}$, as shown in Figures 28 and 29.

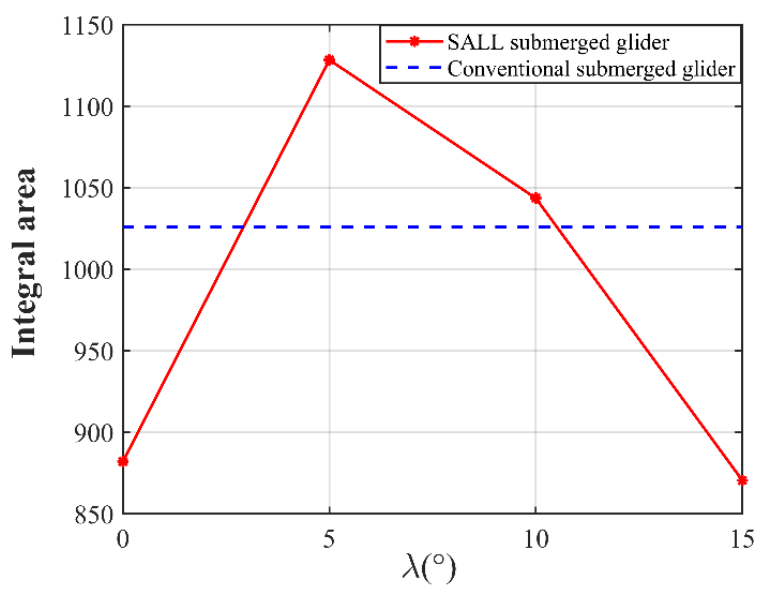

Figure 28. Comparison of integral area under tank experiment.

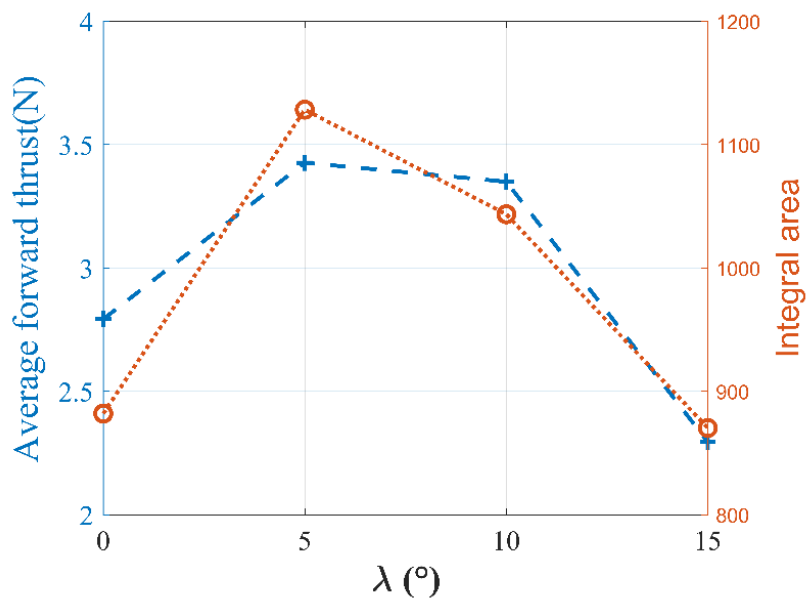

Figure 29. Comparison results of simulation experiment and tank experiment $(K=8)$.

\subsection{Sea Trial}

At 15:53 p.m. on 4 November 2020, a "Black Pearl" wave glider with a SALL mechanism and a "Black Pearl" wave glider with a conventional submerged glider were deployed in the eastern sea area of Qingdao. The course-keeping ability and the forward speed of the two "Black Pearl" wave gliders were tested, and the same navigation algorithm was adopted. The mooring radius was set to $200 \mathrm{~m}$, as shown in Figure 30.

Figure 31 provides the attitude angles of the "Black Pearl" wave glider with the SALL mechanism in the sea trial. Figure 31a illustrates the pitch and roll angles of the submerged glider. The roll angle fluctuated up and down at $0^{\circ}$, and the pitch angle largely ranged from $-10^{\circ}$ to $-20^{\circ}$, which indicates that the attitude of the submerged glider was normal in this sea trial. 


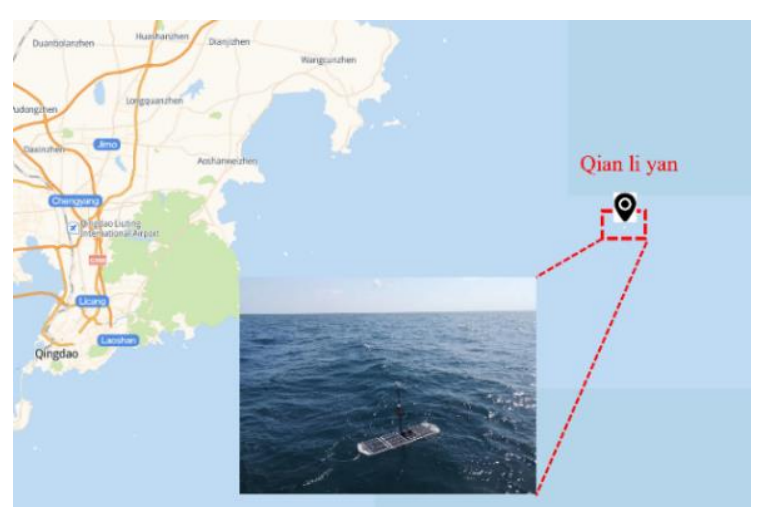

Figure 30. The "Black Pearl" wave glider in the sea trial.

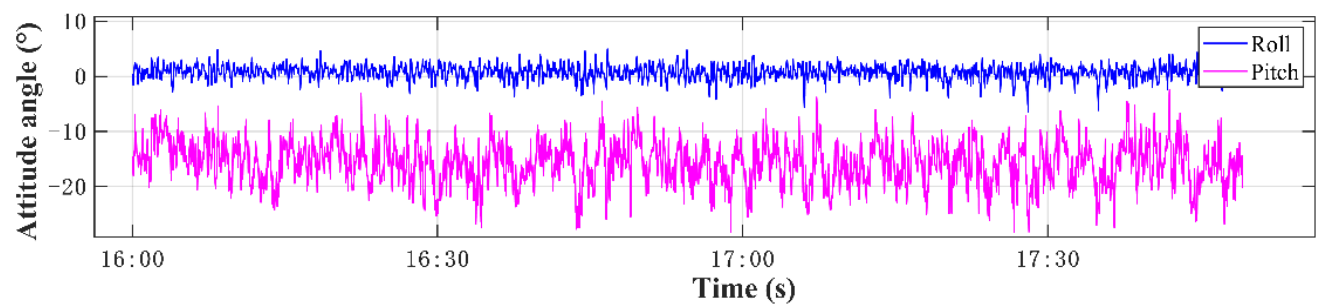

(a)

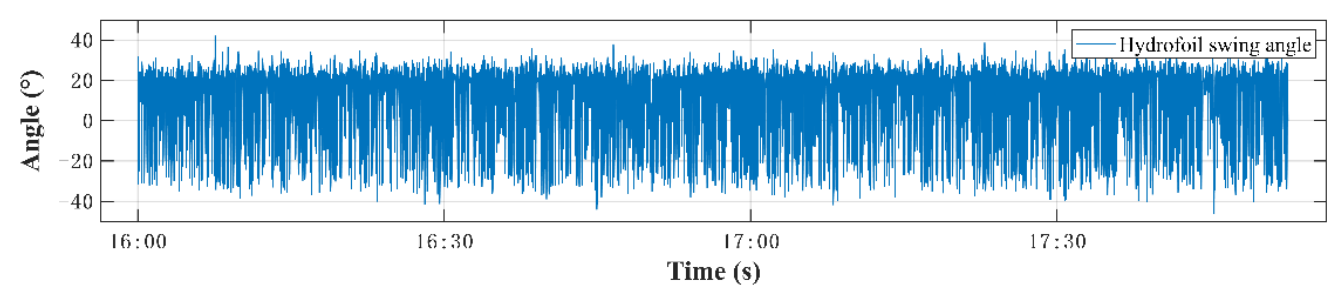

(b)

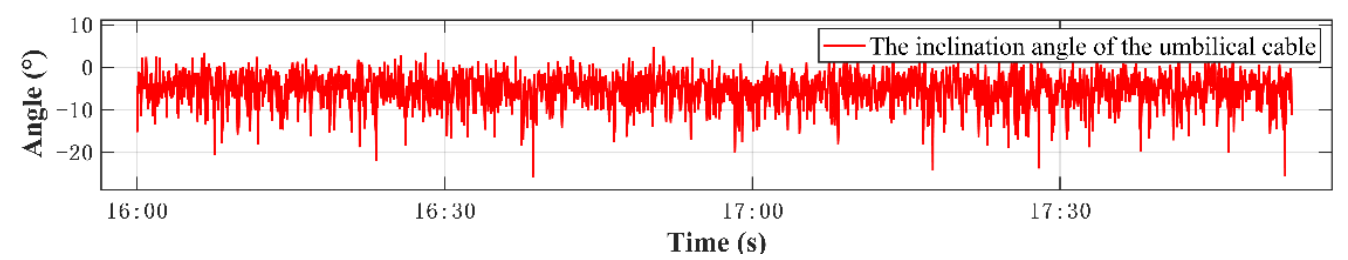

(c)

Figure 31. The attitude angle of the "Black Pearl" wave glider in the sea trial. (a) The pitch and the roll angles; (b) the swing angle of the hydrofoil; and (c) the inclination angle of the umbilical cable.

Figure $3 b$ provides the swing angle of the hydrofoil. When the submerged glider glided downward, the hydrofoil was able to keep a mechanical limit of $20^{\circ}$, and thus the swing angle of the upper limit of the hydrofoil fluctuated in a small range close to $20^{\circ}$. The lower limit of the hydrofoil exhibited an obvious up and down wave dynamic potential, complying with the inclination angle of the umbilical cable, which demonstrated that the swing angle of the hydrofoil was normal. Figure 31c shows the variation of the umbilical cable inclination angle. It is indicated that the umbilical cable inclination angle mainly ranged from $0^{\circ}$ to $10^{\circ}$ in the real sea states.

Figure 32 provides the actual course and the expected course of the two "Black Pearl" wave gliders. Figure 33 illustrates the speed comparisons of the SALL submerged glider and the conventional submerged glider. Figure 34 showcases the trajectories of the SALL submerged glider and the conventional submerged glider. 


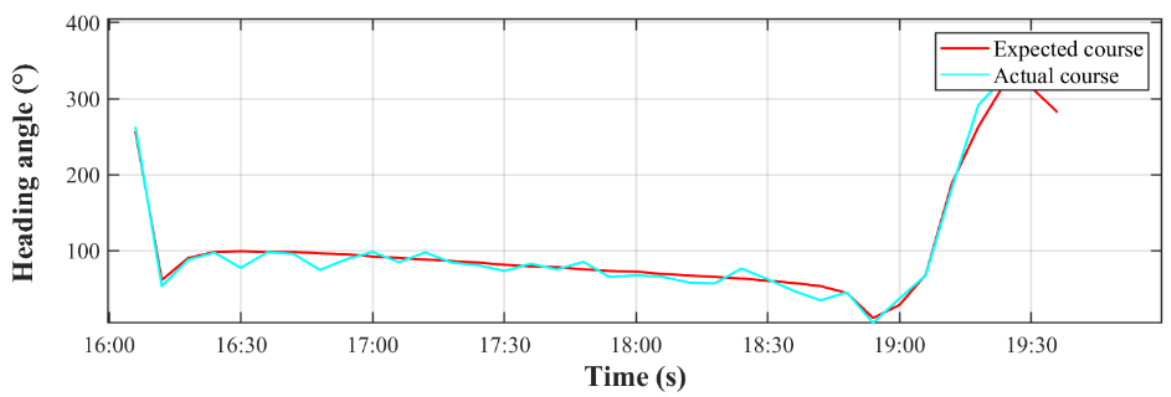

(a)

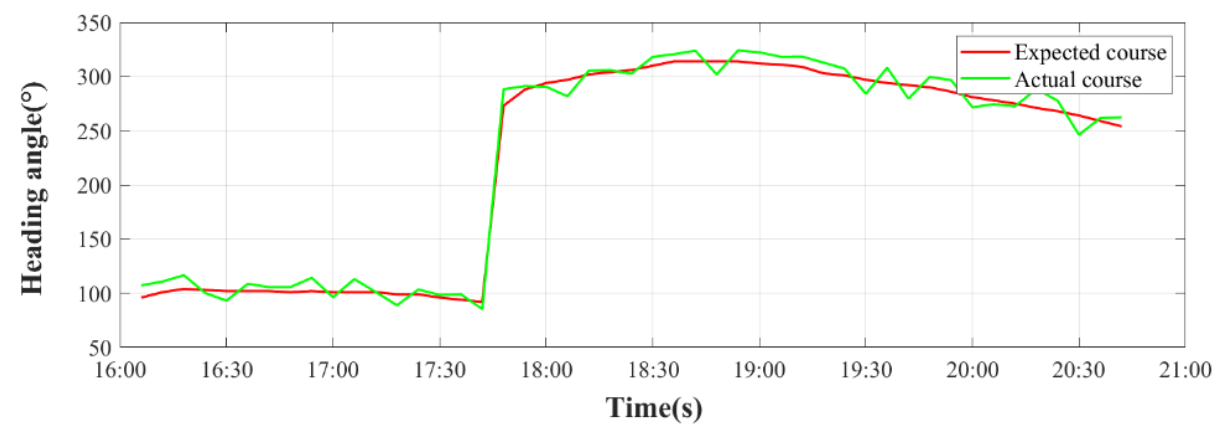

(b)

Figure 32. Comparison of actual course and expected course of the "Black Pearl" wave gliders. (a) The heading angle of the SALL submerged glider; and (b) the heading angle of the conventional submerged glider.

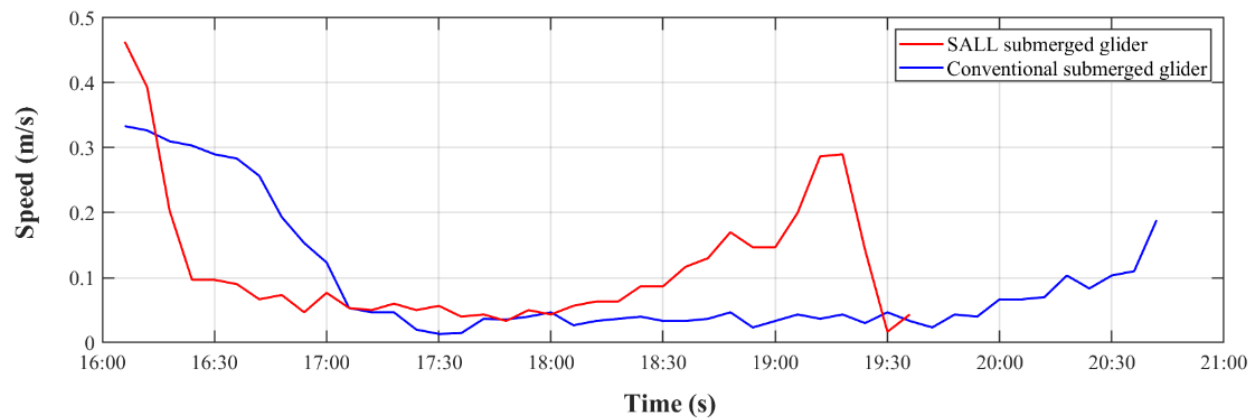

Figure 33. The mooring speed of the "Black Pearl" wave glider.

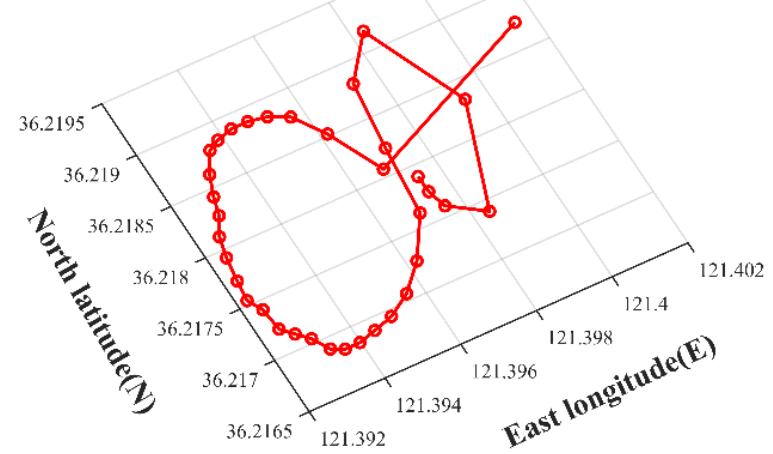

(a)

Figure 34. Cont. 


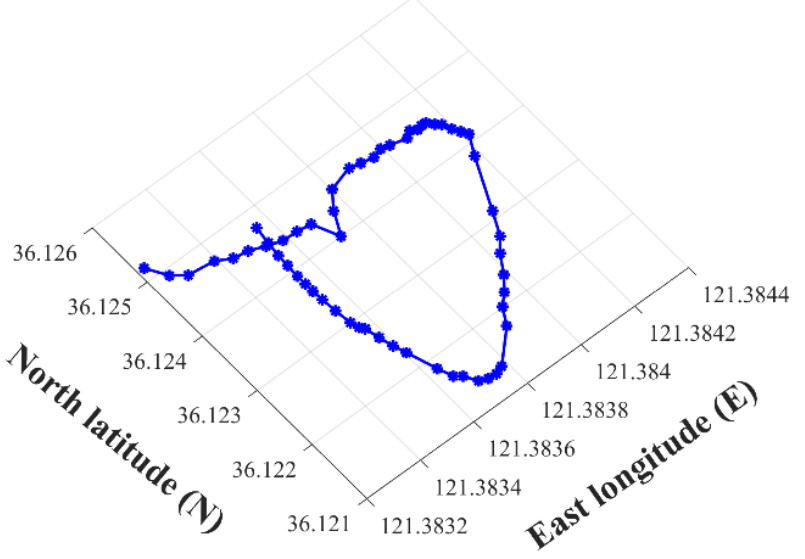

(b)

Figure 34. The trajectories of the two "Black Pearl" wave gliders. (a) The trajectory with the SALL submerged glider; and (b) the trajectory with the conventional submerged glider.

It can be seen from Figures 33 and 34 that the course-keeping capacity of the SALL submerged glider was better than that of the conventional submerged glider, and the mooring speed of the SALL submerged glider was better than that of the conventional submerged glider.

In the same sea conditions, the better the propulsion performance of the wave glider, the stronger the position-holding ability. The circular error probable (CEP) was introduced to evaluate the mooring accuracy of the two wave gliders. The concept of CEP is as follows: for a point dataset, draw a circle with the average center as the center and the CEP as the radius, then $50 \%$ of the points in the point data set will fall into the circle.

The $X$ and $Y$ values of the average center of the point dataset are $\bar{X}$ and $\bar{Y}$, respectively. The standard deviation of $X$ coordinates of all points in the point dataset can be expressed as

$$
\delta_{x}=\sqrt{\frac{\sum\left(X_{i}-\bar{Y}\right)^{2}}{N}}
$$

The standard deviation of $Y$ coordinates of all points in the point dataset can be expressed as

$$
\delta_{y}=\sqrt{\frac{\sum\left(Y_{i}-\bar{Y}\right)^{2}}{N}}
$$

The CEP is defined as

$$
C E P=0.589\left(\delta_{x}+\delta_{y}\right)
$$

There was a clear linear relationship between the difference of longitude and latitude and the difference of actual distance. In order to simplify the calculation, we compared the mooring accuracies of the SALL submerged glider and the conventional submerged glider without calculating the actual mooring radius. The longitude and the latitude were used to calculate the nominal circular error probable $C E P_{n}$.

It can be seen from Table 13 that the $C E P_{n}$ of the SALL submerged glider was significantly smaller than that of the conventional submerged glider. It was indicated that when the same point falling probability was achieved, the mooring radius of the SALL submerged glider was smaller than that of the conventional submerged glider, and the mooring accuracy of the SALL submerged glider was higher than that of the conventional submerged glider. 
Table 13. The $C E P_{n}$ of the SALL submerged glider and the conventional submerged glider.

\begin{tabular}{cccccc}
\hline Submerged Glider & $\overline{\boldsymbol{X}}$ & $\overline{\boldsymbol{Y}}$ & $\delta_{\boldsymbol{x}}$ & $\delta_{\boldsymbol{y}}$ & $\boldsymbol{C E \boldsymbol { P }}_{\mathbf{n}}$ \\
\hline SALL submerged glider & 121.3940 & 36.2178 & 0.001387 & 0.000773 & 0.001272 \\
Conventional submerged glider & 121.3882 & 36.1234 & 0.002244 & 0.001213 & 0.002036 \\
\hline
\end{tabular}

\section{Conclusions}

In this paper, a novel type of the SALL submerged glider was proposed to improve the forward thrust of the wave glider. In real working conditions, the existence of the umbilical cable inclination angle changed the direction of wave energy transmission and reduced the conversion efficiency of wave energy. When we introduced a parallelogram mechanism in the conventional submerged glider, the lower limit of the hydrofoil was able to self-adjust according to the umbilical cable inclination angle. The lower limit of the hydrofoil and the pulling force direction of the umbilical cable can always maintain a fixed gliding angle, and thus the ability of the hydrofoil to capture wave energy can be enhanced. The forward thrust of a pair of hydrofoils with the SALL mechanism was simulated. To assess the propulsive performance of the submerged glider with the SALL mechanism, we carried out the tank experiment and sea trial by using the optimized "Black Pearl" wave glider.

As suggested from the simulation results, when stiffness coefficients of torsion spring were $\mathrm{K}=4, \mathrm{~K}=6$, and $\mathrm{K}=8$, the forward thrusts of the SALL submerged glider were increased by $17.78 \%, 7.42 \%$, and $20.70 \%$, respectively, in comparison with the conventional submerged glider. As suggested from the tank experiment results, under the torsional spring stiffness coefficient $\mathrm{K}=8$, the forward thrusts of the SALL submerged glider were $9.99 \%$ and $1.73 \%$ higher than that of the conventional submerged glider, with follow-up angles of $5^{\circ}$ and $10^{\circ}$, respectively. The optimized "Black Pearl" wave glider was used in an experiment in the eastern waters of Qingdao, China. The feasibility and advantage of the SALL submerged glider was verified by comparing the speeds, the trajectories, and the courses of the "Black Pearl" wave glider, which laid a foundation for further research.

Author Contributions: Conceptualization, H.S. and X.S.; methodology, J.Z. and X.S.; validation, L.W. (Liwei Wang) and C.L.; writing and editing, J.Z. and H.S.; form analysis, C.L. and L.W. (Lei Wang); funding acquisi-tion, X.S. All authors have read and agreed to the published version of the manuscript.

Funding: This research is supported by the National Key Research and Development Program of China (no. SQ2020YFF0426588), the Major Scientific and Technological Innovation Projects of Shandong Province (no. 2019JZZY020701), the National Key Research and Development Plan of China (no. 2017YFC0305902), and the Wenhai Program of Qingdao National Laboratory for Marine Science and Technology (no. 2017WHZZB0101). The authors appreciate all staff members in the research and development team of the "Black Pearl" wave gliders.

Institutional Review Board Statement: Not applicable.

Informed Consent Statement: Not applicable.

Data Availability Statement: Not applicable.

Conflicts of Interest: The authors declare no conflict of interest.

\section{References}

1. Manley, J.; Willcox, S. The Wave Glider: A New Concept for Deploying Ocean Instrumentation. IEEE Instrum. Meas. Mag. 2010, 13, 8-13. [CrossRef]

2. Daniel, T.; Manley, J.; Trenaman, N. The wave glider: Enabling a new approach to persistent ocean observation and research. Ocean Dyn. 2011, 61, 1509-1520. [CrossRef]

3. Yang, F.; Shi, W.; Wang, D. Systematic study on propulsive performance of tandem hydrofoils for a wave glider. Ocean Eng. 2019, 179, 361-370. [CrossRef]

4. Qi, Z.; Zhai, J.; Li, G.; Peng, J. Effects of non-sinusoidal pitching motion on the propulsion performance of an oscillating foil. PLoS ONE 2019, 14, e0218832. [CrossRef] [PubMed] 
5. Javed, A.; Djidjeli, K.; Xing, J.T. Low reynolds number effect on energy extraction performance of semi-passive flapping foil. Appl. Fluid Mech. 2018, 11, 1613-1627. [CrossRef]

6. Zhao, J.; Gao, Z.; Hou, Y.; Hong, X.; Liu, H.; Wang, D. A new method for the structural optimization of a common type of square wing plate used in the wave glider. Ships Offshore Struc. 2018, 14, 755-764. [CrossRef]

7. $\quad$ Feng, Z.; Chang, Z.; Zheng, Z.; Wang, P. Effects of connection type between surface vessel and submersible propeller on motion performance of wave glider. Appl. Sci. 2018, 8, 2467. [CrossRef]

8. Wang, L.; Li, Y.; Liao, Y.; Pan, K. Dynamics modeling of an unmanned wave glider with flexible umbilical. Ocean Eng. 2019, 180, 267-278. [CrossRef]

9. Tian, B.; Yu, J. Current status and prospects of marine renewable energy applied in ocean robots. Int. J. Energy Res. 2019, 43, 2016-2031. [CrossRef]

10. Qi, Z.; Jiang, M.; Jia, L. The effect of mass ratio and damping coefficient on the propulsion performance of the semiactive flapping foil of the wave glider. J. Mar. Sci. Eng. 2020, 8, 303. [CrossRef]

11. Sang, H.Q.; Can, L.I.; Sun, X.J. Quantitative analysis on longitudinal velocity and wave parameter of wave glider. J. Unmanned Undersea Syst. 2018, 26, 16-22.

12. Qi, Z.; Zou, B.; Lu, H.; Shi, J.; Li, G.; Qin, Y. Numerical Investigation of the semi-active flapping foil of the wave glider. J. Mar. Sci. Eng. 2019, 8, 13. [CrossRef]

13. Wang, P.; Tian, X.; Lu, W.; Hu, Z.; Yong, L. Dynamic modeling and simulations of the wave glider. Appl. Math. Model. 2019, 66, 77-96. [CrossRef]

14. Kraus, N.; Bingham, B. Estimation of wave glider dynamics for precise positioning. In Proceedings of the Oceans'11 MTS/IEEE Kona, Waikoloa, HI, USA, 19-22 September 2011; pp. 1-9.

15. Rubenstein, D.A.; Wei, Y.; Frame, M.D. Fundamentals of fluid mechanics. Biofluid Mech. 2012, 31, 15-62.

16. Sun, X.; Zou, Y.; Sang, H.; Yu, P.; Zhang, S. Adaptive path following control for wave gliders in time-varying environment. Ocean Eng. 2020, 218, 108165. [CrossRef]

17. Georgiades, C.; Nahon, M.; Buehler, M. Simulation of an underwater hexapod robot. Ocean Eng. 2009, 36, 39-47. [CrossRef]

18. Liu, P.; Yu, S.U.; Liu, H.X.; Liao, Y.L. Propulsive performance analysis of tandem asynchronous flapping foil. J. Shanghai Jiao Tong Univ. 2014, 48, 457-463.

19. Yang, F.; Shi, W.; Zhou, X.; Guo, B.; Wang, D. Numerical investigation of a wave glider in head seas. Ocean Eng. 2018, 164, 127-138. [CrossRef]

20. Tian, B.; Yu, J.C.; Zhang, A.; Jin, W.; Zhao, W.; Chen, Z. Analysis on movement efficiency for wave driven unmanned surface vehicle. Robot 2014, 36, 43-48 